\title{
Review
}

\section{Targeting CDK9 for Anti-Cancer Therapeutics}

\author{
Ranadip Mandal ${ }^{1}{ }^{(}$, Sven Becker ${ }^{1}$ and Klaus Strebhardt ${ }^{1,2, *}$ \\ 1 Department of Gynecology and Obstetrics, Johann Wolfgang Goethe University, Theodor-Stern-Kai 7, \\ 60590 Frankfurt am Main, Germany; ranadip.mandal@kgu.de (R.M.); sven.becker@kgu.de (S.B.) \\ 2 German Cancer Consortium (DKTK), 69120 Heidelberg, Germany \\ * Correspondence: strebhardt@em.uni-frankfurt.de; Tel.: +49-(049)-069-6301-6894; Fax: +49-(049)-069-6301-6364
}

check for

updates

Citation: Mandal, R.; Becker, S.; Strebhardt, K. Targeting CDK9 for Anti-Cancer Therapeutics. Cancers 2021, 13, 2181. https://doi.org/ 10.3390/cancers13092181

Academic Editor: Claudia Maletzki

Received: 31 March 2021

Accepted: 29 April 2021

Published: 1 May 2021

Publisher's Note: MDPI stays neutral with regard to jurisdictional claims in published maps and institutional affiliations.

Copyright: (c) 2021 by the authors. Licensee MDPI, Basel, Switzerland. This article is an open access article distributed under the terms and conditions of the Creative Commons Attribution (CC BY) license (https:// creativecommons.org/licenses/by/ $4.0 /)$.
Simple Summary: CDK9, in combination with Cyclin T1, is one of the major regulators of RNA Polymerase II mediated productive transcription of critical genes in any cell. The activity of CDK9 is significantly up-regulated in a wide variety of cancer entities, to aid in the overexpression of genes responsible for the regulation of functions, which are beneficial to the cancer cells, like proliferation, survival, cell cycle regulation, DNA damage repair and metastasis. Enhanced CDK9 activity, therefore, leads to poorer prognosis in many cancer types, offering the rationale to target it using small-molecule inhibitors. Several, increasingly specific inhibitors, have been developed, some of which are presently in clinical trials. Other approaches being tested involve combining inhibitors against CDK9 activity with those against CDK9's upstream regulators like BRD4, SEC and HSP90; or downstream effectors like cMYC and MCL-1. The inhibition of CDK9's activity holds the potential to be a highly effective anti-cancer therapeutic.

Abstract: Cyclin Dependent Kinase 9 (CDK9) is one of the most important transcription regulatory members of the CDK family. In conjunction with its main cyclin partner-Cyclin T1, it forms the Positive Transcription Elongation Factor b (P-TEFb) whose primary function in eukaryotic cells is to mediate the positive transcription elongation of nascent mRNA strands, by phosphorylating the S2 residues of the YSPTSPS tandem repeats at the C-terminus domain (CTD) of RNA Polymerase II (RNAP II). To aid in this process, P-TEFb also simultaneously phosphorylates and inactivates a number of negative transcription regulators like 5,6-dichloro-1- $\beta$-D-ribofuranosylbenzimidazole (DRB) Sensitivity-Inducing Factor (DSIF) and Negative Elongation Factor (NELF). Significantly enhanced activity of CDK9 is observed in multiple cancer types, which is universally associated with significantly shortened Overall Survival (OS) of the patients. In these cancer types, CDK9 regulates a plethora of cellular functions including proliferation, survival, cell cycle regulation, DNA damage repair and metastasis. Due to the extremely critical role of CDK9 in cancer cells, inhibiting its functions has been the subject of intense research, resulting the development of multiple, increasingly specific small-molecule inhibitors, some of which are presently in clinical trials. The search for newer generation CDK9 inhibitors with higher specificity and lower potential toxicities and suitable combination therapies continues. In fact, the Phase I clinical trials of the latest, highly specific CDK9 inhibitor BAY1251152, against different solid tumors have shown good anti-tumor and on-target activities and pharmacokinetics, combined with manageable safety profile while the phase I and II clinical trials of another inhibitor AT-7519 have been undertaken or are undergoing. To enhance the effectiveness and target diversity and reduce potential drug-resistance, the future of CDK9 inhibition would likely involve combining CDK9 inhibitors with inhibitors like those against BRD4, SEC, MYC, MCL-1 and HSP90.

Keywords: CDK9; Cyclin T1; RNAP II; Transcription; BRD4; MYC; Apoptosis

\section{Cyclin Dependent Kinases (CDKs)}

Cyclin Dependent Kinases (CDKs) are a family of serine/threonine kinases which require a regulatory cyclin (with the exception of CDK5, which require p35/p39) subunit 
to attain their kinase activity. Presently, this family comprises of 21 members, further classified into three sub-types, broadly based on their regulatory functions: (1) regulators of the cell-cycle-CDKs 1, 2, 4 and 6; (2) regulators of transcription-CDKs 7, 8, 9, 12, 13 and 19; (3) regulators of diverse or as yet undefined functions-CDKs 5, 10, 11, 14, 15, 16, 17, 18 and 20 [1-3]. At present, 29 cyclins have been identified in humans. While, some CDKs can have multiple cyclin partners, some cyclins can also partner with multiple CDKs. There are still some orphan CDKs whose cyclin partners have not been identified (Table 1). This review article is primarily going to focus on CDK9.

Table 1. The different known members of the CDK family, their regulating cyclin partners (except CDK5) and their general functions.

\begin{tabular}{|c|c|c|c|}
\hline & $\begin{array}{l}\text { Cyclin/Regulating } \\
\text { Partners }\end{array}$ & Functions & Reference \\
\hline CDK1 & Cyclin B1 & $\begin{array}{l}\text { Cell-cycle regulation—promotes } \mathrm{G} 2 / \mathrm{M} \text { transition, regulates } \mathrm{G} 1 \text { progress and G1/S } \\
\text { transition }\end{array}$ & {$[4,5]$} \\
\hline CDK2 & Cyclins A/D1/E1 & Cell-cycle regulation-G1/S transition, exit from S-phase; initiation of DNA synthesis & [6] \\
\hline CDK4 & Cyclin D & Cell-cycle regulation-G1-phase transition; partial phosphorylation of $\mathrm{Rb}$ with CDK6 & [7] \\
\hline CDK5 & $\mathrm{p} 35 / \mathrm{p} 39$ & $\begin{array}{c}\text { All aspects of neuronal physiology; immune response; angiogenesis; myogenesis; } \\
\text { melanogenesis and regulation of insulin levels }\end{array}$ & {$[6,8,9]$} \\
\hline CDK6 & Cyclin D & Cell-cycle regulation-G1-phase transition; partial phosphorylation of Rb with CDK4 & [7] \\
\hline CDK7 & Cyclin $\mathrm{H}$ & $\begin{array}{l}\text { CDK Activating Kinase (CAK) - phosphorylates cell-cycle regulating kinases; transcription } \\
\text { regulation-S5 phosphorylation on RNAP II CTD to initiate transcription initiation }\end{array}$ & [10] \\
\hline CDK8 & Cyclin C/Med12/Med13 & $\begin{array}{c}\text { Part of Mediator Complex (MC), regulates the phosphorylation transcription factors, their } \\
\text { activity and turn-over }\end{array}$ & [11] \\
\hline CDK9 & Cyclins T1/T2a/T2b & Positive regulation of transcription elongation & [12] \\
\hline CDK10 & Cyclin M & Cell-cycle regulation and tumor suppressor & {$[13,14]$} \\
\hline CDK12 & Cyclin K & Positive regulation of transcription elongation & {$[15,16]$} \\
\hline CDK13 & Cyclin K & Positive regulation of transcription elongation & {$[15,17]$} \\
\hline CDK14 & Cyclin $\mathrm{Y}$ & Regulation of cell-cycle, proliferation, migration and invasion & [18] \\
\hline CDK15 & Unknown & Inhibits apoptosis by phosphorylating Survivin on T34 & [19] \\
\hline CDK16 & Cyclin Y & $\begin{array}{l}\text { Promotes proliferation in medulloblastoma, prostate, breast, melanoma and cervical } \\
\text { cancers, inhibits apoptosis by down-regulating the tumor suppressor p27 in NSCLC }\end{array}$ & [20-22] \\
\hline CDK17 & Unknown & Down-regulation causes poor prognosis in glioma. Unknown functions & [23] \\
\hline CDK18 & Cyclins A2 and E & $\begin{array}{c}\text { Negative regulator of cell migration and adhesion, prevents the accumulation of DNA } \\
\text { damage and genome instability }\end{array}$ & [24-26] \\
\hline CDK19 & Cyclin C & $\begin{array}{l}\text { CDK8 homolog, part of Mediator Complex }(\mathrm{MC}) \text {, promotes proliferation and mitotic gene } \\
\text { expression in the absence of CDK8 expression, negative regulation of NOTCH signaling }\end{array}$ & [11] \\
\hline CDK20 & $\begin{array}{c}\text { Cyclin H and CK2 } \\
\text { (generic CDK20); } \\
\text { KCNIP2 and SNAPIN } \\
\text { (cardiac CDK20) }\end{array}$ & Cell-cycle regulator (generic CDK20) and promotes cell survival (cardiac CDK20) & [27] \\
\hline CDK21 & Unknown & $\begin{array}{l}\text { Regulates spermatogonial proliferation and meiosis progression and germ line cell } \\
\text { activation in testis; unknown function in cancer }\end{array}$ & [28] \\
\hline
\end{tabular}

\section{CDK9}

\subsection{The Structure of CDK9}

CDK9 was originally discovered by Graña X. et.al. in 1994, in the quest to identify potential CDC2 (CDK1) related kinases, as a $42 \mathrm{kDa}, 372$ amino acid (aa) protein, termed PITALRE due to the presence of a Pro-Ile-Thr-Ala-Lue-Arg-Glu containing motif [29]. This motif corresponded with the highly conserved PSTAIRE box, seen in multiple CDKs (Figures 1 and 2A) [30].

CDK9 exists in two isoforms, the originally identified and more abundant one of 42 $\mathrm{KDa}$ and the less abundant one of $55 \mathrm{kDa}$, the latter having an additional 117 aa at its $\mathrm{N}$-terminus [12]. These two isoforms are transcribed from the same CDK9 gene, but by two different promoters, located more than 500 bp apart on the CDK9 gene, with the 42 $\mathrm{kDa}$ promoter being significantly stronger than the $55 \mathrm{kDa}$ one [31]. Within the nucleus, $\mathrm{CDK} 9_{42}$ is primarily localized within the nucleoplasm while $\mathrm{CDK} 9_{55}$ primarily accumulates within the nucleolus [12] (Figure 2A). All amino acid positions and other aspects of CDK9 mentioned henceforth would be about $\mathrm{CDK} 9_{42}$. 


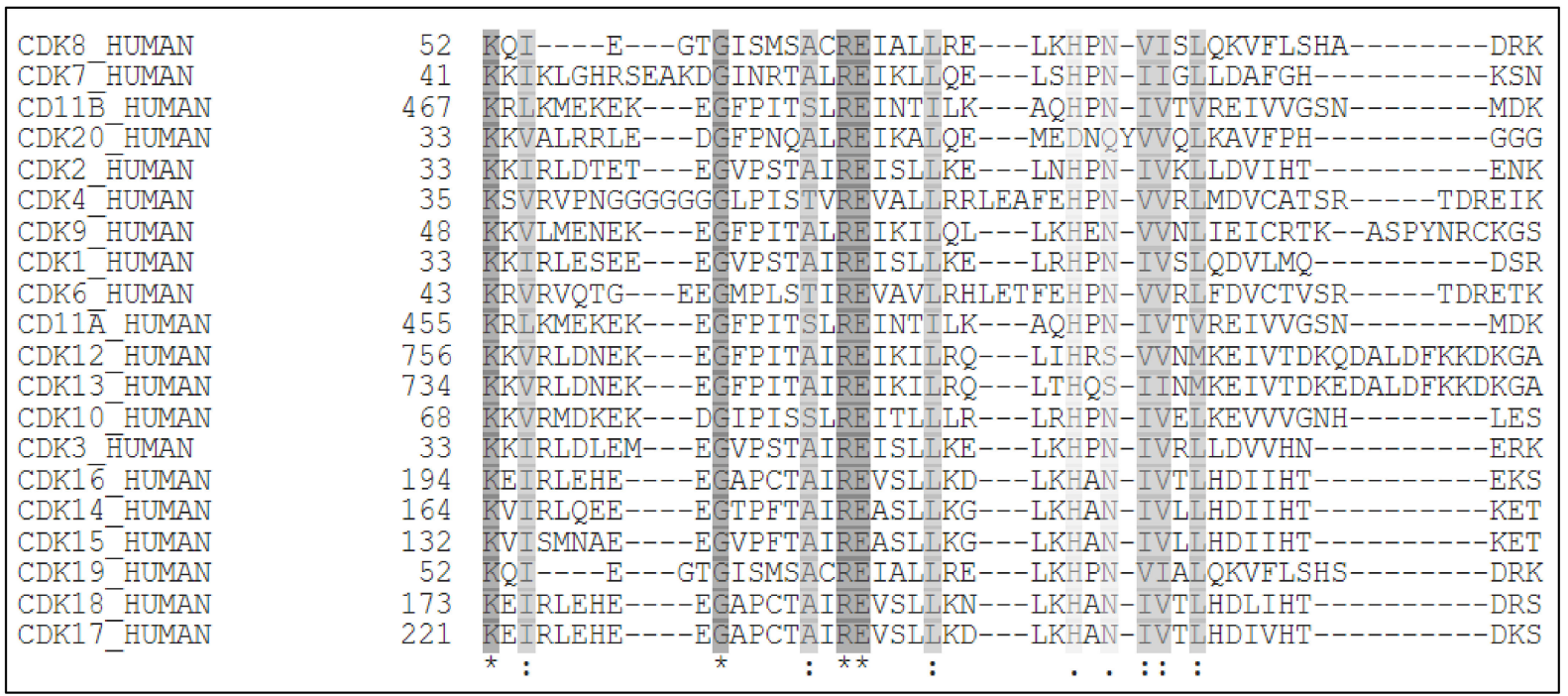

Figure 1. The PITALRE (Pro-Ile-Thr-Ala-Lue-Arg-Glu) sequence of CDK9 which aligned with the highly conserved PSTAIRE box, observed in multiple CDKs.

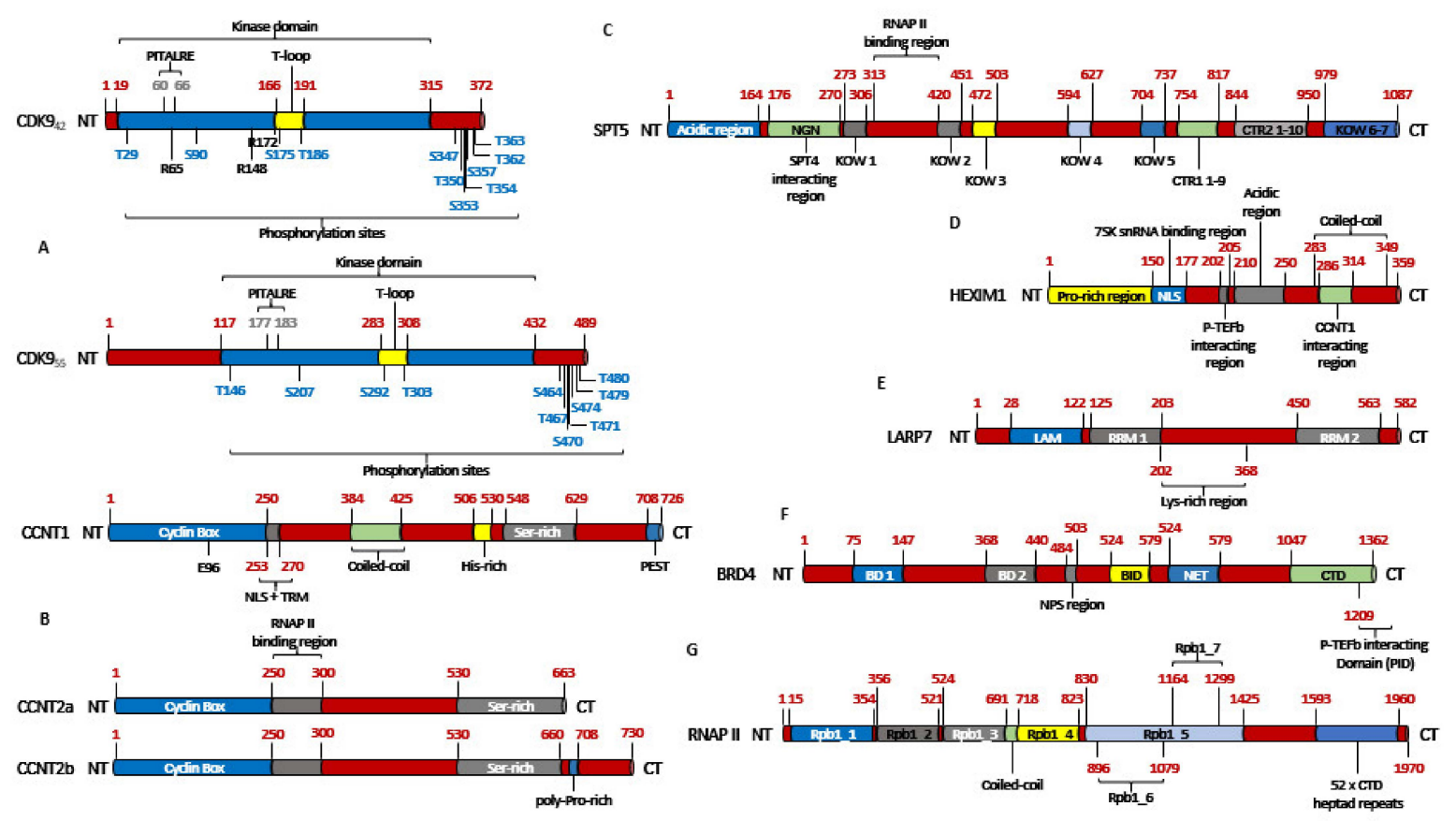

Figure 2. The domain structures of key proteins involved in P-TEFb regulated transcription. (A) The two CDK9 isoforms expressed in most cells. The $\mathrm{CDK}_{55}$ is longer than the $\mathrm{CDK} 9_{42}$ by 117 amino acids (aa) at the N-terminus (NT) as the former isoform is transcribed by a different promoter, $<500$ bp away from the later, on the CDK9 gene. The aa highlighted in blue represent the key phosphorylation sites on CDK9. The PITALRE region is marked in light black. While the three acetylation sites are highlighted in black (B) The three main cyclins that partner with CDK9. The main acetylation site E96 is highlighted in black on Cyclin T1 (C) SPT5 which is a component of the 5,6-dichloro-1- $\beta$-D-ribofuranosylbenzimidazole (DRB) Sensitivity-Inducing Factor (DSIF). It possesses upto 7 Kyrpides-Ouzounis-Woese (KOW) domains which binds to different regions of RNAP II. The RNAP II binding region of SPT5 has been highlighted in black. (D) HEXIM1. (E) LARP7 with its La-Motif (LAM) and RNA-Recognition Motifs (RRM1 and 2). The LAM and RRM1 motifs work synergistically to form a ' $\mathrm{V}$ ' shaped clamp to bind to the 3'-UUUU-OH region of 7SK snRNA while the RRM2 binds to the apical loop of the $3^{\prime}$-hairpin of the 7SK snRNA. (F) BRD4 with its N-terminus Phosphorylation Site (NPS), two Bromodomains (BD1 and 2) and N-terminus Extra Terminal (NET) domain and the C-terminus P-TEFb Interacting Domain (PID). (G) RNAP II with its 7 Rpb1 (RNA polymerase II subunit B1) domains and the $52 \mathrm{Y}_{1} \mathrm{~S}_{2} \mathrm{P}_{3} \mathrm{~T}_{4} \mathrm{~S}_{5} \mathrm{P}_{6} \mathrm{~S}_{7}$ heptad tandem repeats at its CTD. 


\subsection{The Activation of CDK9}

Unlike many CDKs, the activation of CDK9 is not regulated in a cell-cycle dependent manner but by its association with its cyclin partners to form a heterodimeric complex Positive-Transcription Elongation Factor-b (P-TEFb). Even though Cyclin T1 is the primary cyclin partner of CDK9, minor partners like Cyclins T2a and T2b can also activate CDK9 $[1,32,33]$. In fact, in HeLa cells, the shRNA mediated down-regulation of Cyclin T1 led to the down-regulation of 631 genes, as compared to just 292 genes down-regulated upon the knock-down of Cyclin T2 (both Cyclin T2a and Cyclin T2b) [33] (Figure 2B). Initially, Cyclin K was also considered to be another activator of CDK9 [34], however, it is now considered to be a primary activating partner of CDKs 12 and 13 [35,36].

The activity and substrate specificity of $\mathrm{P}-\mathrm{TEFb}$ are decided by the phosphorylation of a number of serine and threonine residues like-T29 and S90 at the N-terminus; S347, T350, S 353, T354, S357, S362 and T363 at the C-terminus; S175 and T186 at the T-loop of CDK9 [30,37-41] (Figure 2A). Amongst them, the phosphorylation of T186 (pT186) is essential for the kinase activity of CDK9 and association with Cyclin T1, as evidenced by the fact that T186A and T186D mutants reduced this association by $\sim 90 \%$ and $~ 50 \%$, respectively, as compared to WT-CDK9 $\left(\mathrm{CDK} 9_{\mathrm{WT}}\right)$ [39]. The analysis of the X-ray crystallographic structure of $\mathrm{P}-\mathrm{TEFb}$ revealed that $\mathrm{T} 186$ was in close proximity and interacts with the arginine residues R148 and R172 [32] and R65 [38] (Figure 2A), to form an intra-molecular H-bond network. T186 was also reported to coordinate and stabilize an inter-molecular salt-bridge between R65 and R172 of CDK9 and E96 of Cyclin T1 (Figure 2B). Like T186A [39], mutations at these three arginine residues (R65A, R148A and R172A) resulted in an almost complete loss of interaction with Cyclin T1, while R65A and R172A also led to a loss of pT186, suggesting a mutual stabilization mechanism. On the other hand, E96A and E96K mutations of Cyclin $\mathrm{T} 1$ caused a partial and complete loss of P-TEFb formation, respectively [38].

Initially, it was reported that, when synthesized, CDK9 undergoes auto-phosphorylation at the T186 residue on its T-loop. When Kim et al. had expressed a mutated CDK9 (T186A) in insect cells using the Baculovirus expression system, no phosphorylation could be detected, even in the presence of Cyclin T1, although, the kinase activity of the mutant remained unimpeded. Incubating CDK9-WT; T186A; and D167N (kinase dead) with the CDK Activating Kinase (CAK; CDK7/Cyclin H), showed a phosphorylation signal only in the $\mathrm{CDK} 9$ WT but in none of the mutants. Even in the presence of Cyclin T1, CAK couldn't enhance the phosphorylation signal of CDK9 above the background level, allowing them to conclude that CDK9 underwent auto-phosphorylation, irrespective of the presence of Cyclin T1 and this phosphorylation was not critical for the kinase activity of CDK9 [42]. CDK9 T186 auto-phosphorylation was also confirmed by Baumli et al. following the mass spectrometric analysis of full-length CDK9, in complex with Cyclin T1 [32].

Larochelle et al. had demonstrated that insect cell-derived $C D K 9_{D 167 \mathrm{~N}}$, both as monomer or in combination with Cyclin T1, purified from bacteria, were phosphorylated at T186 [37], partially contradicting the earlier observation [42]. Similarly, generated CDK9 ${ }_{\text {WT }}$ also showed pT186 and could not be further activated by CAK. However, unphosphorylated WT CDK9, synthesized in vitro by programming rabbit reticulocyte lysates, could not be phosphorylated at T186, even in the presence of Cyclin T1 and ATP, but elicited basal activity towards SPT5. When CAK was introduced into the reaction, pT186 appeared as well as a great enhancement in SPT5 phosphorylation. Similar trend in T186 phosphorylation was also seen with $\mathrm{CDK} 9_{\mathrm{D} 167 \mathrm{~N}}$, albeit at much lower levels and no activity towards SPT5 (Figure 2C) (explained in the following sections). Introducing CAK to this reaction, phosphorylated WT CDK9 at T186 and increased its activity towards SPT5. The CDK9 ${ }_{\text {D167N }}$ was also phosphorylated at T186, albeit at much lower level and had no kinase activity, proving that Cyclin T1 is critical for the activity of CDK9. In HCT116 cell lines, CAK was also shown to be responsible for almost all of pT186, as well as the activation of CDK9 on transcribed chromatin. Additionally, the selective inhibition of CDK7 diminished CDK9 mediated pS2 of RNAP II (Figure 2G) [37]. 
Furthermore, an siRNA library screen of 78 ubiquitously expressed serine/threonine kinases, to identify potential CDK9 T-loop kinases, had revealed the $\mathrm{Ca}^{2+} /$ Calmodulindependent Kinase 1D (CaMK1D) as one such target. Interestingly, although the siRNA mediated knock-down of CaMK1D led to the reduction in pT186, this effect could not be reversed neither by the overexpression of ectopic CaMK1D, nor by increasing $\mathrm{Ca}^{2+}$ levels in HeLa cells. CDK9 and CaMK1D were also not found to interact in either the cytosol or nucleus of HeLa cells, indicating that CaMK1D indirectly affects the CDK9 pT186. In contrast, inhibiting CaMK1D activity by the CaMK inhibitor KN-93 or the CaM inhibitor W-7, led to $59 \%$ and $29 \%$ reduction in pT186 levels, respectively, in HeLa cells. A key takeaway from this work was the revelation that the knock-down of expression or inhibition of activity of CaMK1D also led to the corresponding reduction in total CDK9 levels. This reduction was revealed to be due to the proteasomal degradation of CDK9, which could be partially reversed by treating HeLa cells for $1 \mathrm{~h}$ with the protease inhibitor MG-101 [41].

\subsection{RNA Polymerase II-Mediated Transcription}

The molecular function of CDK9 cannot be described without briefly explaining transcription. In human cells, the expressions of many protein coding genes are regulated by the RNA Polymerase II (RNAP II), at several steps like pre-initiation, initiation, elongation, RNA processing and termination. For the sake of this review, we will briefly focus on some of these steps. Transcription initiation by RNAP II begins with the formation of the Pre-Initiation Complex (PIC) (Figures $3 \mathrm{~A}$ and $4 \mathrm{~A}-\mathrm{C}$ ), for which RNAP II is assisted by General Transcription Factors (GTFs) like TFIIA, TFIIB, TFIID, TFIIE, TFIIF and TFIIH. TFIID in-turn is composed of the TATA box-Binding Protein (TBP), which is required for the transcription from every promoter, and several TBP Associated Factors (TAFs) (Figure 3A), which are required for promoter specific transcription [43-45].

TFIIH is a multi-protein complex, comprising of, in its transcription initiator role-10 proteins (XPB, XPD, p62, p52, p44, p34 and p8 forming the core, plus CAK with CDK7, Cyclin H and MAT1) [46] (Figure 3B). After the formation of the PIC, the transcription of a gene initiates subsequent to the TFIIH mediated-(1) phosphorylation of RNAP II, at the S5 (pS5) residues of the $\mathrm{Y}_{1} \mathrm{~S}_{2} \mathrm{P}_{3} \mathrm{~T}_{4} \mathrm{~S}_{5} \mathrm{P}_{6} \mathrm{~S}_{7}$ tandem repeats and (2) 'promoter melting' which involves opening-up $\sim 10 \mathrm{bp}$ of the promoter dsDNA, allowing RNAP II to access the template strand $[43,47,48]$. The human RNAP II CTD possesses 52 of this heptad repeats [49]. The pS5 also allows the removal of the CDK8 containing Mediator Complex (MC) (Figures $3 \mathrm{D}$ and $4 \mathrm{D}$ ) and the release of RNAP II from the PIC [45]. During transcription initiation, RNAP II generates a nascent transcript $\sim 50$ ribonucleotides from the promoter and then pauses due to the combined effect of two negative regulators-(1) NELF and (2) DSIF (Figure 4D) [50]. One final consequence of the pS5 is the recruitment and activation of capping enzymes which perform a multi-step $5^{\prime}$-capping of the nascent mRNA strand (Figure $4 \mathrm{D}$ ). This capping prevents the degradation of the nascent mRNA strand by nucleases like XRN2 ( $5^{\prime}-3^{\prime}$ exoribonuclease 2$)$ and the resulting termination of the promoter proximally paused RNAP II $[45,51,52]$. The next step in RNAP II mediated transcription is transcriptional elongation by P-TEFb. Interestingly, the regulation of the expressions of most genes in human cells occurs during their transcription elongation, rather than at their initiation phase $[45,53,54]$. Thus, CDK7 aids in both pausing transcription and relieving it by activating CDK9 [38] (Figure 4). 


\subsection{The Molecular Functions of CDK9}

A great deal of the initial information about the function of P-TEFb was obtained by studying its function in HIV-1 transcription, which is regulated by the viral Trans-Activator protein Tat. In the absence of Tat, RNAP II undergoes promoter proximal pausing, in a region adjacent to the Trans-Activation Response element (TAR) RNA sequence, to synthesize short transcripts of $\sim 60$ ribonucleotides $[38,55]$. When present, Tat promotes HIV-1 transcription by first binding to the bulge of the TAR hairpin-loop and then recruiting $\mathrm{P}-\mathrm{TEFb}$, in complex with the Super Elongation Complex (SEC) (Figure 3E), to the HIV-1 promoter. When P-TEFb was knocked-down by siRNA in HeLa cells, it did not cause the cell death but inhibited Tat activation and HIV-1 transcription $[47,56]$. The previously mentioned phosphorylation sites in CDK9-S347, T350, S353, S357 and T354 were found to be essential for the binding of P-TEFb to TAR, as P-TEFb with a C-terminal truncated CDK9 ( $\Delta 323)$, bound to TAR significantly weakly, as compared to CDK9 ${ }_{\text {WT }}[40,57]$. In fact, the then newly found protein was called Cyclin $T$ due to its unique ability to bind with Tat [58]. After two additional Cyclin Ts (T2a and T2b), which cannot interact with Tat, were discovered, the original was termed Cyclin T1 [59].

As mentioned in the previous section, DSIF and NELF are responsible for the promoter proximal pausing of RNAP II (Figure 4F). P-TEFb plays an essential role in promoting transcription elongation by performing three functions that release RNAP II from its pause-(1) phosphorylating NELF, causing its dissociation from the paused RNAP II, (2) phosphorylating the SPT5 subunit of DSIF (Figures 2C and 4F), at T4 of its CTD GS(Q/R)TP residue [60], which subsequent to NELF dissociation, converts into a positive elongation factor and (3) phosphorylating RNAP II at the S2 (pS2) residues of the $\mathrm{Y}_{1} \mathrm{~S}_{2} \mathrm{P}_{3} \mathrm{~T}_{4} \mathrm{~S}_{5} \mathrm{P}_{6} \mathrm{~S}_{7}$ repeats at its CTD. Following the release of RNAP II from its promoter proximal pause, the kinase activity of $\mathrm{P}-\mathrm{TEFb}$ is rendered unnecessary, although it still travels along the Transcription Elongation Complex (TEC) [38,40,50,61].

\subsection{The Regulation of CDK9 Activity}

In order to regulate a highly choreographed process like transcription, the activation and activity of transcription are tightly regulated. In the nuclear extract of HeLa cells, $\sim 80 \%$ of CDK9 was found to be associated with Cyclin T1 (P-TEFb) and 10\% each with Cyclins T2a and T2b [59]. Of these, $~ 50 \%$ of P-TEFb is sequestered in the 7SK snRNP (small nuclear Ribonuclear Protein) $[50,66,67]$ (Figure 3C), which negatively regulates its kinase activity. The 7SK snRNP is composed of the RNAP III transcribed, non-coding 7SK snRNA, which serves as the scaffold for the RNA binding proteins HEXIM1/HEXIM2 (Hexamethylene bis-acetamide inducible proteins) (Figure 2D), LARP7 (La-Related Protein) (Figure 2E) and MePCE (Methylphosphatase Capping Enzyme) [30,50,68]. While HEXIM1 inhibits P-TEFb's kinase activity in a 7SK dependent manner [69], LARP7 stabilizes the 7SK snRNA and protects it from exonuclease meditated degradation by binding to its $3^{\prime}$-UUUU-OH sequence, as evident from the fact that the knock-down of LARP7 resulted in the complete degradation of 7SK snRNA [70,71]. MePCE was originally thought to add a unique $\gamma$-monomethyl phosphate cap to the $5^{\prime}$-end of 7SK snRNA [72], however, recent work had shown that this function existed only in a LARP7 free environment. The presence of LARP7, on one hand, inhibited the capping activity of MePCE, but on the other hand, promoted its interaction with LARP7, to co-operatively stabilize 7SK snRNA [73]. Here too, the CDK9 pT186 played a critical role as $\mathrm{CDK}{ }_{\mathrm{T} 186 \mathrm{~A}}$ or ${ }_{\mathrm{T} 186 \mathrm{D}}$ (Figure $2 \mathrm{~A}$ ) inhibited the associations of the resulting CDK9s to HEXIM1 and LARP7 by 99\%, as compared to CDK9 ${ }_{\mathrm{WT}}$, in Jurkat cells [39] as well as in HeLa cells [74]. Similarly, CDK9 ${ }_{\mathrm{R} 65 \mathrm{~A}}, \mathrm{R} 148 \mathrm{~A}$ and R172A and Cyclin $\mathrm{T} 1_{\mathrm{E} 96 \mathrm{~K}}$ (Figure 2B) were completely incapable of interacting with HEXIM1 and LARP7 [38]. 


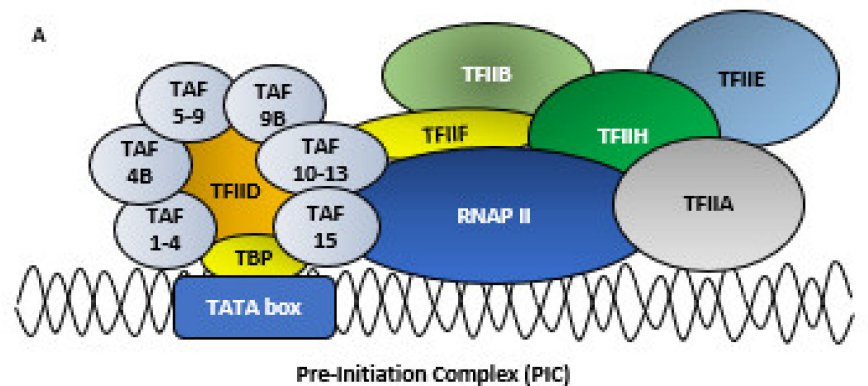

D

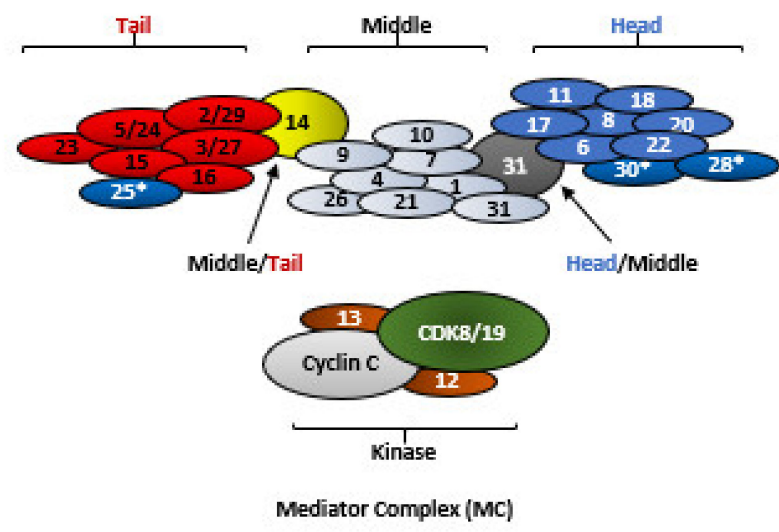

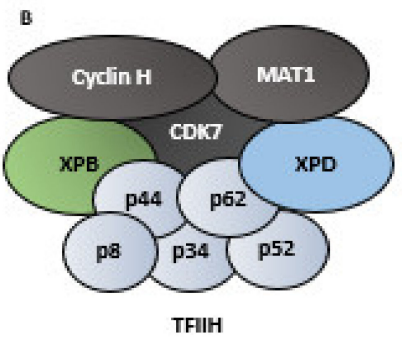

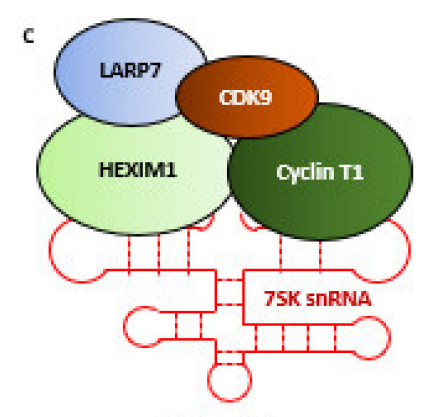

75K snRNP

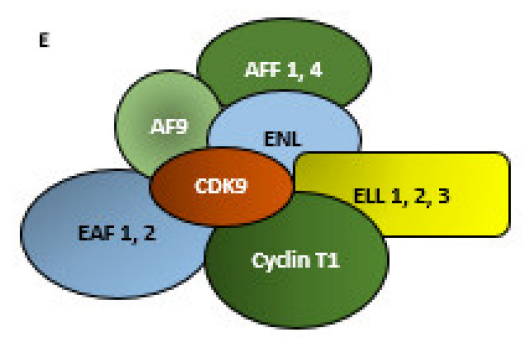

Super Elongation Complex (SEC)

Figure 3. The structures of key complexes involved in RNAP II mediated transcription and regulation of CDK9 activity. (A) Pre-Initiation Complex (PIC)-the PIC is composed of RNAP II which is assisted by General Transcription Factors (GTFs) like TFIIA, TFIIB, TFIID, TFIIE, TFIIF and TFIIH. TFIID in-turn is composed of the TATA box-Binding Protein (TBP) and upto 15 TBP Associated Factors (TAF). TFIID, assisted by TFIIA, first recognizes the core promoter by scanning for and subsequently associating with the TATA box sequence on the promoter DNA. TBP then recruits the TFIIB which subsequently loads the RNAP II-TFIIF complex on the promoter. Eventually, TFIIE and TFIIH facilitates the opening of the transcription bubble [62]. (B) The TFIIH is a heterodecameric protein complex comprising of the proteins XPB, XPD, p62, p52, p44, p34 and p8 forming the core, plus CAK with CDK7, Cyclin H and MAT1. It is an essential part of PIC and is also involved in DNA repair. The DNA helicase XPD and the dsDNA translocase activity of XPB are both required for opening of the transcription bubble, although XPD is not critical for transcription initiation but for DNA damage repair. CAK (CDK7/Cyclin H) phosphorylates S5 of RNAP II, whereas MAT1 both assists in the interaction between CDK7 and Cyclin $\mathrm{H}$ and recruits CAK to the TFIIH core, by interacting with XPD and XPB. The function of XPB is regulated by p52 and $\mathrm{p} 8$ while that of XPD is regulated by $\mathrm{p} 44$ [46]. (C) The 7SK snRNP is composed of the non-coding 7SK snRNA, serving as as scaffold for the RNA binding proteins HEXIM1/HEXIM2, LARP7 and MePCE. (D) The Mediator Complex (MC) is comprised of upto 30 subunits in humans, which are generally divided into the head, middle, tail and kinase modules. The head is composed of the mediators $6,8,11,17,18,20$ and 22 in the head (blue); 1, 4, 7, 9, 10, 21 and 31 in the middle (black); and $15,16,23,2 / 29,3 / 27$ and 5/24 in the tail (red). The mediators 31 and 14 connect the head with middle and tail with middle, respectively. The kinase domain is composed of the mediators 12 and 13, CDK8 or its paralogue CDK19 and Cyclin C. The functions of the mediators 25,28 and $30\left(^{*}\right)$ are yet undefined. The MC promotes the assembly of the PIC by serving as a functional bridge between RNAP II and the above mentioned GTFs [63]. (E) The Super Elongation Complex (SEC) is composed of CDK9/Cyclin T1, the Eleven-nineteen Lysine-rich Leukemia (ELL) proteins 1, 2 and 3, the AF4/FMR2 Family members 1 and 4 (AFF 1 and 4), Eleven-Nineteen Leukemia (ENL), ALL1-Fused gene from chromosome 9 (AF9) and the ELL-associated factors 1 and 2 (EAF 1 and 2) [64,65]. 


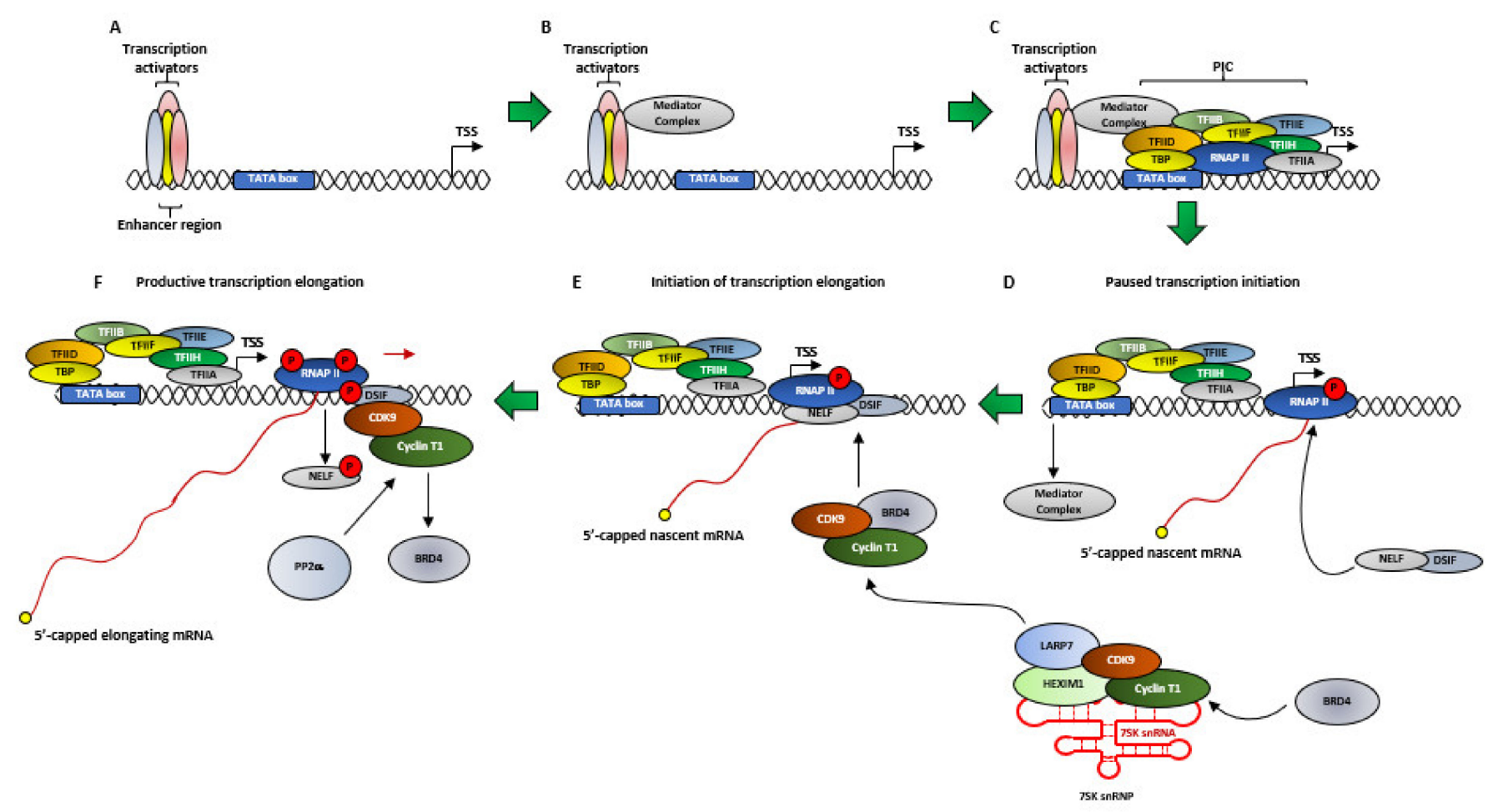

Figure 4. The simplified model of the regulation of transcription by P-TEFb. (A) At the beginning of transcription, Transcription Factors (TFs) bind to the enhancer regions, upstream of the core promoter region (represented by the TATA box). The TATA box in-turn is located upstream of the Transcription Start Site (TSS). (B) TFs recruit the Mediator Complex (MC) (Simplified here from Figure 3). (C) The MC then assists in the recruitment and assembly of the PIC on the DNA strand which, as mentioned before, starts promoter melting and form the transcription bubble, to allow to the RNAP II to access the DNA template strand. (D) The TFIIH subunit of PIC also phosphorylates the S5 residue at the CTD of RNAP II to initiate transcription from the TSS to generate a nascent mRNA transcript of $\sim 50$ ribonucleotides but pauses due to recruitment of two negative regulators of transcription DSIF and NELF. The S5 phosphorylation also enables the dissociation of the MC and freeing-up of the RNAP II from the PIC and promotes the recruitment of capping enzymes to cap the $5^{\prime}$-end of the nascent mRNA strand in a multi-step process, to prevent the nascent strand from being degraded by nucleases like XRN2. The cap remains until transcription finishes and the mRNA is properly processed. (E) When it is ideal for the cells to carry-out productive transcription, BRD4 recruits P-TEFb (CDK9/Cyclin T1) from its negative regulatory complex-7SK snRNP to the RNAP II. However, the kinase activity of the BRD4 bound CDK9 remains transiently inhibited due to the phosphorylation of T29 of CDK9 by BRD4 (F) The phosphatase PP2 $\alpha$ is then recruited which dephosphorylates $\mathrm{T} 29$, restoring the kinase activity of CDK9. This causes the additional P-TEFb mediated phosphorylations of RNAP II at S2, the SPT5 subunit of DSIF at T4 and NELF. This allows NELF to dissociate from RNAP II, which along with SPT5 phosphorylation, transforms DSIF to a positive elongation factor. These events relieve RNAP II from transcription pause and allows it to progress along with the DNA template to initiate productive transcriptional elongation. As the transcription elongation gears-up, BRD4 was released from the $\mathrm{P}-\mathrm{TEFb}$.

The remaining 50\% P-TEFb was associated with BRD4 (Figure 2F) or with the SEC (Figure 3E). BRD4 is the only member of the Bromodomain and Extraterminal (BET) protein family capable of binding with $\mathrm{P}-\mathrm{TEFb}[30,75]$. Unlike the inactive $\mathrm{P}-\mathrm{TEFb}$ in the 7SK snRNP complex, P-TEFb associated with BRD4 was active and was recruited to various promoters via BRD4's interactions with acetylated histones-H3, H4 and MC [76,77]. Interestingly, P-TEFb remained associated with BRD4 since the formation of PIC until the initiation of transcription elongation [30]. Under physiological conditions, the EAF1 and 2 of SEC (Figure 3E) interacted with the med26 subunit of the MC (Figure 3D) to get directly recruited to genes like MYC and HSP70. ChIP-seq analysis following med26 depletion resulted in lower occupancy of SEC components throughout the complete transcribed regions of the aforementioned two genes, as well as reduced levels of S2 RNAP II on these genes. However, with some genes, SEC recruitment required the pre-occupancy of BRD4, 
while in others, the RNAP II associated factor (PAF1) recruited SEC by interacting with AF9 or ENL [64,65].

Multiple hypothesis had been put forth to explain the interaction between BRD4 and $\mathrm{P}-\mathrm{TEFb}$. Zhou et al. had reported that BRD4, bound to P-TEFb, was recruited to HIV PIC (Figures $3 \mathrm{~A}$ and $4 \mathrm{E}$ ) where, in order to subsequently facilitate the formation of an efficient TEC, transiently inhibited the kinase activity of P-TEFb by auto-phosphorylating the T29 of CDK9. As the PIC gears-up for transcription elongation, between positions $+1-+14$ for HIV-1, BRD4 was released from the TEC. The phosphatase PP2 $\alpha$ was then recruited to the TEC, which de-phosphorylated T29, restoring the kinase activity of P-TEFb [78]. Schröder et al. had proposed a 'two-pronged' binding mechanism between BRD4 and P-TEFb, where on one hand, the N-terminal Bromodomain (BD2) of BRD4 (Figure 2F) interacted with at least 3 of the 4 known acetylated lysine residues of Cyclin T1 (K380ac, K386ac and K390ac), while P-TEFb was still bound to HEXIM1 and 7SK snRNA. On the other hand, the C-terminal 54 aa long P-TEFb Interacting Domain (PID) of BRD4 (Figure 2F) interacted with the active P-TEFb, devoid of both HEXIM1 and 7SK snRNA, by dissociating HEXIM1 from Cyclin T1. This marked the transition between inactive and active $\mathrm{P}-\mathrm{TEFb}$ in the presence of BRD4. Of note, BD1 showed no binding affinity towards Cyclin T1 and the affinity of BD2 towards the tri-acetylated Cyclin T1 was similar to its affinity towards acetylated histones [79]. This finding was further corroborated by Itzen et al. who had demonstrated that in vitro, PID stimulated the kinase activity of P-TEFb by $\sim 1.3$ folds over its basal activity, even in the presence of HEXIM1 (Figure 2D). By performing Isothermal Titration Calorimetry, they had also demonstrated that PID did not bind to Cyclin T1, in the absence of CDK9, thereby proposing that the Bromodomain and PID interacted synergistically with Cyclin T1 and CDK9 of P-TEFb, respectively, forming a stable clamp 900 aa apart. Interestingly, PID-P-TEFb interaction did not alter the phosphorylation specificity and substrate preference for CDK9 at the CTD of RNAP II [80]. Yang et al. had also reported the importance of a new CDK9 phosphorylation site-S175, in the biding of P-TEFb with BRD4. When mutated to CDK9 ${ }_{\mathrm{S} 175 \mathrm{~A} / \mathrm{D}}$ in HeLa cells, the association of the mutant CDK9 with BRD4 was completely abolished, without affecting the association with either Cyclin T1 or HEXIM1, indicating that the pS175 is necessary for the association of P-TEFb with BRD4 and its resulting dissociation from the inactive 7SK snRNP complex $[74,81]$. This was also confirmed by Mbonye et al. in T-cells $[38,39]$. On the other hand, CDK9 $9186 \mathrm{~A} / \mathrm{E}$ almost completely abolished the association of the mutant CDK9 with HEXIM1 but not with Cyclin T1 or BRD4, confirming the need for this phospho-site for HEXIM1 binding [81,82], although Mbonye et al. had shown that $\mathrm{CDK}^{\mathrm{T} 186 \mathrm{~A}}$ couldn't interact with Cyclin $\mathrm{T} 1$ [38]. The kinase responsible for the pS175 was eventually identified as CDK7. Treatment of Jurkat cells with PMA led to the partial dissociation of P-TEFb from the 7SK snRNP (Figure 3C) and therefore pS175 level, which was effectively inhibited by the selective CDK7 inhibitor THZ1. pT186 remained unaffected [38].

From all these and other works, it has become evident that BRD4 and other promoterspecific TFs are necessary to retrieve the active P-TEFb from the 7SK snRNP complex and carry out transcription elongation.

\subsection{The Other Pool of CDK9}

As mentioned earlier, $\sim 80 \%$ of CDK9 existed as P-TEFb, whether sequestered as an inactive complex with 7SK snRNP or as an active complex with BRD4 or other TFs. But, what about the remaining 20\% CDK9, unbound to Cyclin T1? O'Keeffe et al. had demonstrated that free CDK9 was unstable within the cells and got degraded rapidly. In $293 \mathrm{~T}$ cells, stably expressing a HA-tagged CDK9, $\sim 80 \%$ of the newly synthesized HACDK9 was degraded within the first 6-12 $\mathrm{h}$, whereas the remaining 20\% HA-CDK9 did not show any significant degradation until $48 \mathrm{~h}$. They were the first to identify that CDK9 bound to two chaperones-the more general HSP70 and the substrate specific HSP90/CDC37 complex, which acted in a sequential manner. Initially, HSP70 stabilized any newly synthesized CDK9 by correctly folding it. Once the nascent CDK9 attained a 
certain folded configuration, it was handed over to the HSP90/CDC37 complex, which established and maintained the CDK9 for the follow-up binding to Cyclin T1, thereby completing the final assembly of P-TEFb. The inhibition of HSP90's interaction potential by the inhibitor Geldanamycin led to $\sim 12.5$ folds increase in HSP70 bound HA-CDK9. The erstwhile mentioned stable $\sim 20 \%$ CDK9 comprised of these three complexes [83]. More recently, Mbonye et al. had confirmed these findings in T-cells. They had also described that in the absence of Cyclin T1 expression, as in resting T-cells, HSP90/CDC37 bound CDK9 was predominantly localized within the cytosol and lacked any pT186. Upon undergoing TCR activation, resulting in Cyclin T1 expression, CDK9 was imported to the nucleus to get activated. Once again, the treatment of Th17 cells with the Geldanamycin derivative-17-AAG significantly reduced the formation of $\mathrm{P}-\mathrm{TEFb}$ and the expression of Cyclin T1, possibly through proteasomal its degradation. Additionally, the association of CDK9 with HSP90/CDC37 showed a minor, but significant, uptick in CDK9 ${ }_{\text {T186A }}$ [38]. Indeed, Napolitano et al., had demonstrated that CDK9 could be detected in both the cytosol and the nucleus, while Cyclin T1 was predominantly localized within the nucleus. Our own work in this direction has also confirmed this in multiple cervical, breast and ovarian cancer cell lines (un-published work) [84,85]. It was also shown that CDK9 could shuttle between the nucleus and cytosol, via the CRM1/exportin protein and inhibiting the association between CDK9 and CRM1 by the nuclear export inhibitor LMB (Leptomycin B) enriched nuclear CDK9. Additionally, it was demonstrated that the expression of Cyclin T1 promoted the nuclear localization of CDK9 [86,87].

\section{The Clinical Relevance of CDK9}

CDK9 expression had been implicated in the prognosis and resistance to anti-cancer therapeutics in a large number of cancer types like those of breast, lung, prostate, endometrium, apart from melanoma, osteosarcoma, myeloid leukemia, soft tissue sarcomas etc. [1,88-92]. We will briefly explain some of these cancer entities here.

\subsection{Breast Cancer}

$\mathrm{ER} \alpha^{+}$endocrine therapy-resistant breast cancers over-expressed the cMYC oncogene and genes regulated by it [93] which correlated with poor RFS, but not when the patients had only undergone chemotherapy [89]. In a study on breast cancer cell lines, Sengupta et al. had demonstrated that in multiple aromatase inhibitor-resistant MCF-7 cancer cell lines, the levels of cMYC mRNA and proteins were significantly higher than the parental MCF-7 cell line. In these cell lines, the cMYC promoter showed higher recruitment of pS2, but not pS5 in RNAP II, as compared to MCF-7 cells, which also correlated with higher levels of both pT186 and CDK9 (2.5 and 3.1 folds, respectively). Lastly, the inhibition of CDK9 activity, in the resistant cell lines, with the small-molecule inhibitor CAN-508, showed a dose-dependent inhibition of cell growth, in conjunction with $\sim 60 \%$ reduction in cMYC mRNA and proteins, highlighting the critical role of CDK9 in the up-regulation of cMYC expression in endocrine therapy-resistant $\mathrm{ER} \alpha^{+}$breast cancer patients [89].

\subsection{Osteosarcoma}

Similarly, Ma et al. had demonstrated that, of 70 osteosarcoma patient derived samples, $67.1 \%$ exhibited high CDK9 expression, which significantly correlated with metastatic disease, non-survival, worse OS (Overall Survival) and DFS (Disease Free Survival) and poor post-neoadjuvant chemotherapy necrosis. CDK9 expression was also higher in osteosarcoma cell lines, as compared to the osteoblast cell line HOB-c. Down-regulating CDK9 (siCDK9) expression led to decreased cell proliferation, as well as reduced levels of pS2 RNAP II and MCL-1 whereas, treating the osteosarcoma cell lines with the ATP competitive CDK9 inhibitor LDC000067 significantly reduced the levels of pS2 RNAP II and MCL-1 and their clonogenicity, in a dose-dependent manner, in conjunction with increased apoptosis. 12 days of treatment with $10 \mu \mathrm{M}$ of LDC000067 also significantly 
reduced the diameters of the 3D spheroids of U2OS (57.4\%) and KHOS (48.8\%) cell lines, as compared to their untreated counterparts [88,94].

\subsection{Endometrial Cancer}

Of the 32 endometrial cancer patient samples (carcinosarcoma-2, clear cell-2, serous-4, mixed cell-2, mucinous- 1 and endometrioid-21), analyzed by He et al., 59.4\% had low and $40.6 \%$ had high CDK9 expression, but demonstrated no correlation between these expression values and the pathological stage, grade and sub-type of endometrial tumor. As seen before, high CDK9 expression significantly worsened the OS (39 vs. 14 months) and PFS (Progression Free Survival) (96 vs. 26 months). Concentration dependent knock-down of CDK9 expression and dose-dependent inhibition of CDK9 activity by LDC000067 led to correspondingly significant reductions in cell viability and MCL-1 expression while BAX expression and PARP cleavage were enhanced. Additionally, 14 days of treatment with increasing concentrations of LDC000067 resulted in significant reductions of clonogenicity and 2D migration of endometrial cancer cell lines [90].

\section{4. $A M L$}

The dysregulation of the CDK9 pathway was also reported by various groups in AML. Increased expressions of $\mathrm{CMYC}$ and MCL-1 had been associated with the pathogenicity of AML due to the enhanced survival and expansion of the AML cells. High MCL-1 expression was also observed in and associated with poor prognosis in $~ 50 \%$ of R/R AML cases. Translocation products of the MLL (Mixed Lineage Leukemia) gene were found to associate with $\mathrm{P}-\mathrm{TEFb}$ in AML to trigger constitutively active transcription [95]. Its levels were found to be $\sim 2$ folds higher in recurrent patients as compared to pre-treatment patients, while its down-regulation led to the death of both human and murine AML cells $[96,97]$. As a result, targeting the anti-apoptotic BCL-2 family members, to which MCL-1 belongs, had been attempted. Venetoclax is one such inhibitor which was approved by the FDA in 2020, for use against newly diagnosed AML patients of 75 years or older, in combination with Azacitidine, Decitabine or Low-Dose Cytarabine (LDAC). Unfortunately, MCL-1 up-regulation enables Venetoclax resistance and relapse. Combining Venetoclax with the CDK9 inhibitor Alvociclib had shown synergistic effect against both Venetoclax resistant and sensitive AML patients, in a pre-clinical study $[97,98]$.

On the other hand, in primary AML samples, the mRNAs of HEXIM1 and cMYC were found to be over-expressed with mutual exclusivity [99]. HEXIM1 served as the binding partner of several other proteins, nearly half of which has been recognized for their roles in cancers. In AML, the cytoplasmic-mislocated mutant of the p53 regulator NPM (Nucleoplasmin)-NPMc ${ }^{+}$, was observed in $~ 35 \%$ of all AML patients. Both NPM and $\mathrm{NPMc}^{+}$were HEXIM1 binding proteins. NPM overexpression induced the proteasomal degradation of HEXIM1, thereby freeing-up P-TEFb to regulate enhanced transcription elongation. $\mathrm{NPMc}^{+}$had a disrupted NLS and an extra NES, thereby localizing the resulting protein to the cytoplasm instead of the nucleoli, as seen with NPM. NPMc ${ }^{+}$sequestered HEXIM1 from its usual nuclear location to the cytoplasm, again hampering the formation of the negative regulatory 7SK snRNP complex, leading to the increased P-TEFb mediated transcription elongation [100].

\subsection{Lung Cancer}

The pro-inflammatory cytokine TNF $\alpha$ stimulated the expression of the Matrix Metalloproteinase-9 (MMP-9) in an NF- $\mathrm{kB}$ dependent manner, which promoted cancer cell migration and invasion, by degrading basement membrane, and also angiogenesis, by vascular structure remodeling and the release of angiogenic factors like VEGF (Vascular Endothelial Growth Factor) [101,102]. Shan et al. had demonstrated that in the lung adenocarcinoma cell line A549, TNF $\alpha$ stimulated the transcription of the MMP-9 promoter. To achieve this, TNF $\alpha$ enhanced the associations of both $\mathrm{CDK} 9_{55}$ and $\mathrm{CDK} 9_{42}$ to Cyclin T1, as well as the binding of P-TEFb to the MMP9 gene which led to increased 
levels pS2 RNAP II bound to MMP9. The P-TEFb inhibitor DRB substantially inhibited TNF $\alpha$ stimulated MMP-9 mRNA expression by $\sim 76$ folds and its activity by $\sim 80 \%$, but not those of TGF- 11 stimulated MMP-2. Similarly, the over-expression of a double-negative CDK9 (CDK9dn) or an siCDK9 lowered the TNF $\alpha$ stimulated MMP-9 activity by more than half. Additionally, CDK9 positively regulated the NF- $\mathrm{kB}$ response element, through which TNF $\alpha$ stimulated the transcription of the MMP-9 promoter. Once again, DRB as well as CDK9dn blocked the activation of NF- $\mathrm{kB}$ by TNF $\alpha$ [103]. More recently a novel highly selective CDK9 inhibitor-21e, was shown to inhibit CDK9 activity $\left(\mathrm{IC}_{50} 11 \mathrm{nM}\right)$ in NSCLC cells as well as cell lines of other cancer entities. It suppressed the clonogenicity of two NSCLC cell lines while inducing apoptosis by down-regulating the expression of BCL-2 and up-regulating the pro-apoptotic protein BIM, as well as increasing Caspase-3 activation. 21e also significantly inhibited pS2 RNAP II. Inhibiting CDK9 activity also suppressed the expressions of the stemness markers in the two NSCLC cell lines-SOX2, OCT4, NANOG and KIF4, while also significantly inhibiting other stemness phenotypes like Side Population (SP) and serum-free suspension culture. Lastly, 21e also inhibited the tumor growth of a mouse xenograft model derived from the NSCLC cell line H1299, once more validating the significance of CDK9 in lung cancer [104].

\subsection{Prostate Cancer}

Androgen Receptor (AR), a steroid receptor TF for testosterone and di-hydrotestosterone, played a critical role in prostate cancer, especially in the castration resistant sub-type. AR mutations, Post-Translational Modifications (PTMs), over-expression and splice variants were some of the ways through which prostate cancers evaded Androgen Ablation Therapy (AAT) [105]. AR was compartmentalized in the cytoplasm in an inactive form, in complex with HSP90, which sequestered it from migrating into the nucleus and binding to the DNA. In the presence of suitable steroid ligands, AR underwent a conformational change and detached from the HSP90. The conformationally changed AR then underwent homo-dimerization and translocated to the nucleus, where it bound to Androgen Response Element (ARE) located at the promoters of the target genes. The phosphorylation of AR is one PTM which resulted in its altered-activation, transcriptional activity, stability, nuclear retention and cell growth. 18 such phosphorylation sites are currently known [106], among which, S81 is most frequently phosphorylated in response to androgen stimulation, by kinases like CDK1 [107,108], CDK5 [109] and CDK9 [110]. Mutating this phosphorylation site to S81A resulted in the reduced cell growth and altered the transcription of the AR regulated genes in a promoter specific manner. In vitro, CDK9 phosphorylated S81 exclusively and ex vivo, under basal conditions, WT-CDK9/Cyclin T1 could but CDK9dn/Cyclin T1 could not phosphorylate S81, but in the presence of the synthetic androgen R1881, both constructs could phosphorylate S81, albeit to a lower level for CDK9dn/Cyclin T1. siCDK9 treatment also led to a significant reduction in pS81, in the presence of R1881. Similarly, inhibiting CDK9 activity by DRB or Flavopiridol treatment reduced pS81 signal in a dosedependent manner, in conjunction with the reduced transcription of the AR regulated early response genes-SGK1 and NKX3.1 [110]. Chen et al. had shown that while CDK1 mediated pS81 increased during mitosis, CDK9 performed this function during the interphase of androgen responsive $\mathrm{LNCaP}$ and non-responsive PC3 prostate cancer cell lines. Additionally, CDK9 mediated pS81 stabilized AR chromatin binding for transcription [107].

\subsection{Melanoma}

CDK9 has been reported to be overexpressed in many melanoma cell lines [111] while CDKs 7 and 9 were also shown to be over-expressed in multiple uveal melanoma cell lines. Using the potent CDK7/9 inhibitor-SNS-032, it was demonstrated that pS2/5/7 at RNAP II, by these two kinases, could be inhibited in a dose-dependent manner, resulting in reduced cell proliferation, migration, invasion, cancer stemness, in vivo tumor formation, increased MMP-9, but not MMP-2, expression, in dose- and time-dependent manners. Under similar conditions, increased apoptosis of the treated cells was also observed, both 
ex and in vivo, accompanied by enhanced PARP and Caspase- 3 cleavages and reduced expressions of several anti-apoptotic proteins. Lastly, SNS-032 also led to reduced transcription and expressions of YAP (Yes Associated Protein) and its active form pYAP (S127). All these alterations were attributed directly to the inhibition of CDK7 /9 by SNS-032 [112].

Recently, Zhang, et al. had demonstrated that the CSN6, a member of the Constitutive Photomorphogenesis 9 (COP9) Signalosome (CSN) complex family, was over-expressed in malignant melanoma cell lines and tissues, driving their proliferation, migration and invasion. CSN6 was shown to interact with CDK9, stabilizing and protecting the latter from being ubiquitinated and subsequently degraded by UBR5 (Ubiquitin Protein ligase E3 component n-recognin 5), in the malignant melanoma cell lines A375 and MV3. Mouse xenograft models of A375 cells with stable knock-down of CSN6 manifested significantly smaller tumors and CDK9 positive cells, as compared to those derived from CSN6 expressing cells. These effects of CSN6 knock-down could be significantly rescued by concurrent knock-down of UBR5, highlighting the significance of CDK9 in melanoma [113]. As CSN6 expression is up-regulated in multiple cancer entities [113-115], it stands to reason that this effect, demonstrated in melanoma could occur in other cancer types too.

\subsection{Ovarian Cancer}

Amongst 26 primary ovarian cancer patient samples (serous-20, squamous-1, highgrade serous-1, endometroid-1, transitional cell-1, endometroid and serous-1 and endometroid and clear cell-1), Wang et al. had shown significantly lower CDK9 expression in primary cancer tissues than patient-paired metastatic and recurrent cancer tissues. Of these, 13 patients with lower CDK9 expression had better DFS and OS, as compared to those with higher expression. No correlations were observed between CDK9 expression and the stage, grade, subtype and ascites of the ovarian cancer patients. Similar to endometrial cancer and osteosarcoma, use of siCDK9 and LDC000067 resulted in a dose-dependent inhibition of cell-viability and a decrease in pS2 of RNAP II, MCL-1 levels and an increase in BAX expression and PARP cleavage. Additionally, LDC000067 treatment led to significant reductions of clonogenicity, 2D migration and 3D spheroid formations of two ovarian cancer cell lines-SKOV-3 and OVCAR-8, once again highlighting the significance of CDK9 in the poor prognosis of ovarian cancer [116].

\section{Inhibitors of CDK9}

A number of CDK9 inhibitors have been reported over the years, including many pan-CDK inhibitors (Table 2). Cassandri et al., in their review article, had listed a number of natural CDK targeting compounds like Indirubins, isolated from several indigo producing plants. A couple of synthetic derivatives of Indirubins like 6-bromoindirubin and 6-bromoindirubin-3'-monooxime were also reported [1]. Another natural compound Rohitukine, with anti-inflammatory and anti-immunomodulatory properties, derived from the Dysoxylum binectariferum plant, served as the basis for one of the earliest pan-CDK inhibitor Flavopiridol [117]. In this review, we would briefly describe Flavopiridol, as it was the first CDK9 inhibitor to enter clinical trials [118], and some of the other more recent, selective inhibitors, although not all of them entered the clinical trials phase (Table 2).

\subsection{Flavivirid}

Flavopiridol (Alvocidib) (Table 2) is a semi-synthetic flavonoid alkaloid derivative of Rohitukine, discovered following an NCI based screening of 72,000 compounds against 60 human cancer cell lines [119]. Initially, Flavopiridol showed inhibitory activities against EGFR and PKA ( $\mathrm{IC}_{50} 21$ and $122 \mu \mathrm{M}$, respectively), however, during the NCI screen, it exhibited growth inhibition at $\mathrm{IC}_{50} 66 \mathrm{nM}, \sim 1000$ folds lower than the concentrations required for EGFR and PKA inhibition [120]. Its remarkable anti-proliferative and growth inhibitory effects, in vivo and ex vivo, respectively, were initially attributed to its activity against CDKs 1, 2, 4 and 7. Eventually, it was found to be most effective against CDK9 [121]. Flavopiridol is an ATP-competitive inhibitor, which showed promising in vitro activity 
against a number of cancer entities, but demonstrated only limited in vivo activity, except in hematologic cancers like MCL and CLL, resulting in the cessation of its further development $[1,122]$. Presently, only three trials, involving Flavopiridol, are active, against AML, advanced solid tumors and Myelodysplastic Syndromes (MDS). Dinaciclib (SCH-727965) was developed as next generation inhibitor, based on Flavopiridol. Dinaciclib inhibited CDKs $1,2,5$ and 9 with respective in vivo $\mathrm{IC}_{50}$ of $3,1,1$ and $4 \mathrm{nM}$, as compared to 3, 12, 14 and $4 \mathrm{nM}$ for its predecessor. It also triggered apoptosis and arrested cell-growth in $>100$ tumor cell lines [123,124]. However, preliminary results from clinical trials have been reported to be less encouraging [122]. Further trials are ongoing (Table 2).

\subsection{AZD-4573}

The development of the highly selective CDK9 inhibitor AZD-4573 (Table 2) was based on another selective, oral inhibitor of the amidopyridine series-AZ-5576, which was reasonably potent against the AML cell line MV-4-11, both ex and in vivo, but exhibited lower solubility in PBS and rate of metabolism in human microsomes, limiting its ability to provide a high therapeutic dose and optimal duration of target engagement within the clinical scenario. AZD-4573 showcased excellent selectivity against CDK9 with in vitro $\mathrm{IC}_{50}$, measured using the Thermofisher Kinase Panel, at $<4 \mathrm{nM}$, as compared to 117, 52, 23, 499, 1270, 363, 1370 and $8070 \mathrm{nM}$ against CDKs 1, 2, 3, 4, 5, 6, 7 and 12, respectively. Twice daily i.p. administration (bid) of 5 and $15 \mathrm{mg} / \mathrm{kg}$ AZD-4573 resulted in $97 \%$ and $100 \%$ tumor growth inhibition, respectively, for MV-4-11 and 65\% inhibition, for both doses, against Nomo-1 based AML xenograft mouse models, along with reductions in pS2, MCL-1 levels and increase in Caspase-3 cleavage. In MCF-7 cells, AZD-4573 had an $\mathrm{IC}_{50}$ of $14 \mathrm{nM}$ against CDK9, as compared with $370 \mathrm{nM}, 1100$ and $>10 \mu \mathrm{M}$ against CDKs 1, 4/6/7 and $2 / 4 / 6$, respectively. Both the mRNA and protein levels of MCL- 1 were down-regulated in a dose-dependent manner, without affecting the same for other anti-apoptotic proteins like BCL-2 and BCL-XL. Caspase-3 cleavage was also observed in MV-4-11 and MOLM-8 cell lines, suggesting that MCL- 1 is the major initiator of AZD- 4573 driven apoptosis. Against a diverse panel of cancer cell lines, 6 and $24 \mathrm{~h}$ of AZD-4573 treatment generated significant Caspase- 3 activation and reduction in viability, more pronouncedly in hematological cancer cell lines than in solid tumor cell lines. The pharmacokinetics (PK) and pharmacodynamics (PD) of AZD-4573 also improved in vivo over AZ-5576 [125,126]. Presently, AZD-4573 is subject to two phase-I clinical trials against advanced hematological cancers (NCT04630756) [127] and relapsed/refractory hematological cancers (NCT03263637) [128] (Table 2).

\subsection{BAY-1143572 (Atuveciclib)}

Atuveciclib (Table 2) was discovered by Lücking et al. in search of a highly selective, orally applicable and exclusive P-TEFb inhibitor. The basis for Atuveciclib design was the triazine BAY-958, which demonstrated in vitro $\mathrm{IC}_{50}$ of $11 \mathrm{nM}$ against $\mathrm{CDK} 9$ and a CDK2/CDK9 $\mathrm{IC}_{50}$ ratio of 98, but slow absorption and low oral bioavailability in vivo. Atuveciclib displayed in vitro $\mathrm{IC}_{50}$ of $13 \mathrm{nM}$ against $\mathrm{CDK} 9$ and an $\mathrm{IC}_{50}$ ratio of 100. Ex vivo $\mathrm{IC}_{50}$ against $\mathrm{CDK} 9$ were $0.92,0.31$ and $0.89 \mu \mathrm{M}$ in HeLa, MOLM-13 and MV-14 cell lines, respectively, with excellent anti-proliferative effect. In vivo, BAY-1143572 showed markedly lower blood clearance and improved oral bioavailability. In MV-14 AML cell line derived rat xenograft, daily oral administration of $12 \mathrm{mg} / \mathrm{kg}$ of BAY- 1143572 for 14 days resulted in no tumor re-growth in 9/12 animals [129]. Owing to these promising pre-clinical results, BAY-1143572 was subjected to two Phase-I studies against advanced malignancies (lymphomas and solid tumors; NCT01938638) and acute leukemia (NCT02345382). In both cases however, due to high drug related TEAE (Treatment Emergent Adverse Effect) and lack of clinal response at the dose tested, both trials were pre-maturely terminated $[130,131]$ (Table 2). 


\subsection{BAY-1251152}

BAY-1251152 (Table 2) was a follow-up, P-TEFb inhibitor of BAY-1143572, with increased potency, with $\mathrm{IC}_{50}$ against CDK9 under both in vitro and ex vivo (MOLM-13 cells) conditions being 3 and $29 \mathrm{nM}$, respectively; enhanced selectivity against CDK2; permeability; solubility; and no efflux. BAY-1251152 also demonstrated impressive in vivo efficacy in MOLM-13 derived xenograft mouse and rat models [132]. In our own studies, BAY-1251152 had demonstrated $\mathrm{IC}_{50}$ of 19.06, 16.57 and $74.64 \mathrm{nM}$ against HeLa, SiHa and OVCAR-3 cells, respectively, as compared to comparative BAY-1143572 $\mathrm{IC}_{50}$ of 1.27 and $0.64 \mu \mathrm{M}$ for HeLa and SiHa cells (un-published work). Until the development of AZD-4573, BAY-1251152 was the only selective CDK9 inhibitor currently undergoing clinical trials [133] against advanced malignancies (NHL and solid tumors; NCT02635672). This phase-I study revealed significant, dose-dependent reductions in the mRNA levels of MYC, PCNA and MCL-1 and manageable safety. There were also signs of anti-tumor activity viz. stable disease (SD) in $9 / 31(29 \%)$ and durable SD in 3/31 (9.7\%) patients [134]. Another phase-I trial against advanced hematological malignancies (NCT02745743) is ongoing. Preliminary results from AML patients revealed significant, but short-lived post-treatment reductions in the mRNA levels of $M Y C(0.5-4 \mathrm{~h}), P C N A(1-4 \mathrm{~h})$ and $M C L-1(1-3 \mathrm{~h})$. No objective responses were achieved at any doses, despite achieving CDK9 inhibition [135]. Additionally, BAY-1251152 monotherapy was declared to generate durable remissions of over two years in $2 / 7 \mathrm{pa}-$ tients with very aggressive relapsed/refractory double-hit DLBCL (Diffused Large B-Cell Lymphoma), following a phase-I trial [136] (Table 2).

\subsection{SNS-032 (BMS-387032)}

SNS-032 (Table 2), was originally shown as a selective CDK2 inhibitor, but was later shown to be able to inhibit CDK7 and CDK9, with modest inhibitory activities against CDKs $1,4,5$ and 6 . In vitro kinase profiling revealed $\mathrm{IC}_{50}$ values of $38-48 \mathrm{nM}(\mathrm{CDK} 2), 62 \mathrm{nM}$ (CDK7), $4 \mathrm{nM}$ (CDK9), $480 \mathrm{nM}$ (CDK1), $925 \mathrm{nM}$ (CDK4), $340 \mathrm{nM}$ (CDK5) and >1000 nM (CDK6) [137], while Albert et al. reported these values, respectively, at $6 \mathrm{nM}$ (CDK2), $68 \mathrm{nM}$ (CDK7), $1.4 \mathrm{nM}$ (CDK9), $52 \mathrm{nM}$ (CDK1), $355 \mathrm{nM}$ (CDK4) and $3404 \mathrm{nM}$ (CDK6) (no CDK5 values were reported) [138]. Ex vivo IC 50 values were 231 and $192 \mathrm{nM}$ against CDKs 7 and 9, respectively, in RPMI-8226 cells, along with reductions in pS5 and 2 of RNAP II, XIAP and MCL-1 levels and increased PARP cleavage [137]. In a phase-I clinical trial involving patients with advanced solid tumors, high SNS-032 concentrations inhibited pS5 and 2 of RNAP II and MCL-1 expression, in their PBMCs. However, all 20 participants of this study discontinued treatment due to relapse or disease progression $(65 \%)$; deterioration without progress (20\%); adverse effect (5\%); drug-related toxicity (5\%); and patient request (5\%). Only 3 patients exhibited SD following treatment [139]. Another phase-I pharmacological study (NCT00446342) against 19 CLL and 18 MM patients, identified MTD (Maximum Tolerated Dose) and DLT of 75 and $100 \mathrm{mg} / \mathrm{m}^{2}$, respectively, for the CLL patients. MTD could not be established while DLT was not observed for the MM patients. Overall, SNS032 was well tolerated by both patient types, at all infusion doses and induced reductions in pS5 and 2 of RNAP II, within $2 \mathrm{~h}$ of starting the infusion, reverting to baseline levels after $24 \mathrm{~h}$. At $6 \mathrm{~h}$, when the infusion was stopped, the reduction of pS2 level was more pronounced (64\%) than pS5 level (35\%), along with XIAP (10\%) and MCL-1 (56\%) levels and increased PARP cleavage. However, SNS-032 only exhibited limited anti-tumor activities in both the CLL (1 partial and 1 stable diseases) and MM cohorts (1 stable disease), with the treatment of all three stable cases terminated due to drug-related toxicities, patient request or investigator decision [140]. A third clinical trial of SNS-032 against solid tumors was also completed, although its results have not yet been posted (NCT00292864) (Table 2).

Olson et al. had recently demonstrated that conjugating a Thalidomide group to SNS-032, to produce THAL-SNS-032, could selectively and potently degrade CDK9, but no other CDK targets of SNS-032, in a CRBN dependent manner. Compared to SNS-032, THAL-SNS-032 exhibited in vitro IC $_{50}$ values of $171 \mathrm{nM}$ (CDK1), $62 \mathrm{nM}$ (CDK2), $398 \mathrm{nM}$ (CDK7), $4 \mathrm{nM}$ (CDK9). Against a panel of leukemia cell lines, THAL-SNS-032 demonstrated 
anti-proliferative effects at $\mathrm{IC}_{50}$ values 2-6.5 folds lower than those of SNS-032. It also inhibited pS2, in MOLT4 AML cells, in a time- and dose-dependent manner, but pS5 and 7 levels remained completely unaffected. While both SNS-032 and its derivative similarly induced PARP and Caspase-3 cleavages, only THAL-SNS-032 induced MCL-1 degradation and $\gamma$ H2A.X activation in MOLT4 cells [141], unlike in RPMI-8226 cells [139]. Reduction in global gene expression was also significantly more pronounced after THAL-SNS-032 treatment, as compared to its predecessor [141]. In short, addition of the Thalidomide group to SNS-032, turned a pan-CDK inhibitor into a highly selective CDK9 inhibitor. Due to the CRBN-mediated ubiquitination and degradation of CDK9, the mechanisms of THAL-SNS-032-mediated induction of apoptosis and inhibition of the transcriptional machinery was also different than that of SNS-032, which only inhibited the activations of CDKs 2, 7 and 9. No clinical trials of THAL-SNS-032 has been initiated till date (Table 2).

\subsection{AT-7519}

AT-7519 (Table 2) is a pan-CDK inhibitor developed by Wyatt et al., that selectively inhibited CDKs with in vitro IC 50 values of $190 \mathrm{nM}$ (CDK1), $47 \mathrm{nM}$ (CDK2), $67 \mathrm{nM}$ (CDK4) and $18 \mathrm{nM}$ (CDK5). It showed low oral bioavailability. Intraperitoneal injection for 8 days BID of AT-7519 in A2780 derived ovarian cancer xenograft mouse model produced $86 \%$ tumor growth inhibition at $7.5 \mathrm{mg} / \mathrm{kg}$ dose [142]. Squires et al. later identified CDK9 as a target for AT-7519 with in vitro IC 50 values of $210 \mathrm{nM}$ (CDK1), $47 \mathrm{nM}$ (CDK2), $100 \mathrm{nM}$ (CDK4), $13 \mathrm{nM}$ (CDK5), $170 \mathrm{nM}$ (CDK5) and $<10 \mathrm{nM}$ (CDK9). AT-7519 exhibited antiproliferative effect against 26 cancer cell lines at IC $\mathrm{C}_{50}$ values of $40-940 \mathrm{nM} .24 \mathrm{~h}$ of treatment of HCT-116 cells as a consequence of the inhibitions phosphorylations of substrates of CDK1 (PP1 $\alpha$ at pT320) and CDK2 (Rb at pT821 and NPM at pT199). Global transcription was also inhibited at $\mathrm{IC}_{50}$ of $56 \mathrm{nM}$ due to the inhibition of CDK9 mediated phosphorylation of S2 on RNAP II, within $4 \mathrm{~h}$ of treating HCT-116 cells with AT-7519. $24 \mathrm{~h}$ treatment with this inhibitor resulted in cell-cycle blockades at G0/G1 and G2/M phases, causing a reduction in S-phase and increase in G2/M phase cells and apoptosis. 9 days BID of AT-7519 in HCT116 derived colon cancer xenograft mouse model caused complete tumor regression for upto 24 days at $9.1 \mathrm{mg} / \mathrm{kg}$ dose [143]. AT-7519 also inhibited pS2 in the HL-60 cell line, reductions in MCL-1 levels and global transcription at $\mathrm{IC}_{50}$ of $34 \mathrm{nM}$. HL-60 xenograft model displayed inhibited pT199, pT821 for upto $16 \mathrm{~h}$ and MCL-1 for $24 \mathrm{~h}$, and PARP cleavage, following a single dose of $10 \mathrm{mg} / \mathrm{kg}$ of AT-7519. In patient derived CLL cells, AT-7519 treatment displayed time-dependent cytotoxicity; induced apoptosis, irrespective of time and dose; inhibited pS2; reduced MCL-1 protein and mRNA; and induced PARP cleavage, in a dose-dependent manner [144]. Multiple phase I and II clinical trials have been undertaken with AT-7519 [145]. In a phase I study involving patients with advanced/metastatic solid tumors and refractory NHL (NCT00390117), 19/32 showed SD from 2.5-11.1 months, with a median duration of 3.3 months. Intravenous administration was well tolerated and served as the basis of two phase-II trials involving MCL (NCT01652144) and CLL (NCT01627054) [146]. In both these trials, although the inhibitor was well tolerated by most patients, only modest clinical activity was observed at the tested dose and schedule [147]. Another phase I study evaluating the combination of the HSP90 inhibitor-Onalespib and AT-7519 involving advanced/metastatic/unresectable solid tumors is currently active (NCT02503709) [148] (Table 2).

\subsection{NVP-2}

NVP-2 (Table 2) is a highly selective aminopyrimidine-derived CDK9 inhibitor, developed by Novartis. In vitro IC 50 NVP-2 against CDK9 was $<0.5 \mathrm{nM}$ as compared to $584 \mathrm{nM}$ (CDK1), $706 \mathrm{nM}$ (CDK2), $1050 \mathrm{nM}$ (CDK5) and $>10 \mu \mathrm{M}$ (CDK7). When used against MOLT4 cells, NVP-2 inhibited cell proliferation with an $\mathrm{IC}_{50}$ of $9 \mathrm{nM}$, as well as apoptosis induction after $4 \mathrm{~h}$ of treatment, as evidenced by PARP and Caspase- 3 cleavages and complete loss of MCL-1, lasting for $24 \mathrm{~h}$. Washout experiments in these cells showed a marked decrease in cell viability, accompanied by PARP and Caspase- 3 cleavages and $\gamma \mathrm{H} 2 \mathrm{~A} . \mathrm{X}$ activation, even 
$72 \mathrm{~h}$ after NVP-2 removal. The inhibitor also reduced pS2 levels and a significant decrease in global mRNA expression, including 2-4 $\log 2$ fold reduction in CRC (Core Regulatory Circuitry) genes like MYC, MYB and RUNX1. ChIP-seq analysis following NVP-2 treatment revealed increased levels of promoter-proximal paused RNAP II at the TSS (Transcription Start Site), with corresponding decrease in RNAP II level all-over the gene body, including at the MYC, MYB and RUNX1 loci. CDK9 inhibition also caused gene body wide loss of SPT5 [118,141]. These data demonstrated that NVP-2 is a small-molecule CDK9 inhibitor with tremendous clinical potential, however, no clinical trial has been reported till date (Table 2).

\subsection{JSH-150}

JSH-150 (Table 2) is a recently synthesized, highly selective CDK9 inhibitor with in vitro $\mathrm{IC}_{50}$ values of, determined using the Invitrogen SelectScreen platform, $1 \mathrm{nM}$ (CDK9) and $1.34 \mu \mathrm{M}$ (CDK1), $2.86 \mu \mathrm{M}$ (CDK2), $4.64 \mu \mathrm{M}$ (CDK5) and $1.72 \mu \mathrm{M}$ (CDK7). JSH150 bound to CDK9 via five H-bonds-C106 in the hinge region (2), D109 (1), D167 in the activation loop (1) and T29 in the P-loop (1). Its GI $_{50}$ (concentration of an inhibitor causing $50 \%$ of maximum inhibition in cell proliferation) against multiple solid and hematologic cancer cell lines ranged from 1.1-44 nM as compared to $1100 \mathrm{nM}$ against CHO cells. $2 \mathrm{~h}$ of treatment of the cell lines HL-60 and MV4-11 (AML) and MEC-1 (CLL) did not affect the phosphorylation of CDK9 at T186 and RNAP II at S5; XIAP and BCL-2 levels but inhibited pS2 $\left(\mathrm{EC}_{50}<100 \mathrm{nM}\right), \mathrm{MCL}-1$ and cMYC levels, in a dose-dependent manner. Treatment for $24 \mathrm{~h}$ induced PARP and Caspase- 3 cleavages in all three cell lines, as well as cell cycle arrest at the G0/G1 phase. In vivo, $T_{\max }$ and $\mathrm{T}_{1 / 2}$ were 2 and $3.33 \mathrm{~h}$; and 1.55 and $3.37 \mathrm{~h}$ in mice and rats, respectively. JSH-150 was also orally bio-available with bio-availabilities of 45.01 and $45.10 \%$ in mice and rats, respectively. MV4-11 derived mouse xenograft models, 20 and $30 \mathrm{mg} / \mathrm{kg} /$ day of JSH-150 treatment for 14 days, suppressed tumor progression, without causing general cytotoxicities or tumor recurrence, one week after the treatment was stopped [149]. No clinical trial of JSH-150 has been reported so far (Table 2).

\section{9. $L Y-2857785$}

LY-2857785 (Table 2) is a reversible, ATP-competitive inhibitor, demonstrating in vitro $\mathrm{IC}_{50}$ values of $246 \mathrm{nM}(\mathrm{CDK} 7), 16 \mathrm{nM}$ (CDK8) and $11 \mathrm{nM}$ (CDK9). Against a panel of 114 kinases, it showed $\mathrm{IC}_{50}$ of $<100 \mathrm{nM}$ against only 5 other kinases. In U2OS cells, LY-2857785 targeted pS5 and 2 of RNAP II with $\mathrm{IC}_{50}$ of 89 and $42 \mathrm{nM}$, respectively, and inhibited cell proliferation at $\mathrm{IC}_{50}$ of $76 \mathrm{nM}$. No cell-cycle arrest was detected. It also inhibited cell proliferation of the leukemic cell lines MV-4-11, RPMI-8226 and L363 at IC 50 of 40, 200 and $500 \mathrm{nM}$, following 4-24 h of treatment, and induced apoptosis in a time-dependent manner. Levels of XIAP and MCL-1 were also reduced and triggered PARP and Caspase-3 cleavages. Proliferation of other AML cell lines were also inhibited. In HCT116-derived mouse xenograft model, LY-2857785 treatment inhibited pS2 in a dose-dependent manner with a $\mathrm{TED}_{50}$ of $4.4 \mathrm{mg} / \mathrm{kg}$ (Threshold Effective Dose). Multiple AML xenograft models also showed dose-dependent tumor regression. Moreover, LY-2857785 showed good solubility for and pharmacokinetics. Unfortunately, it also exhibited anti-proliferative properties towards normal hematopoietic progenitor cells of humans (ex vivo), rats and dogs (ex and in vivo), causing in vivo hemetoxicity of bone marrow, gastrointestinal tract and other organs in dogs. As a result, the further clinical development of LY-2857785 was discontinued [150]. 


\subsection{0. $L D C 000067$}

LDC000067 (Table 2) was synthesized by Albert et al. as an ATP competitive inhibitor with in vitro $\mathrm{IC}_{50}$ of $44 \mathrm{nM}$ (CDK9), $2.4 \mu \mathrm{M}$ (CDK2) and $>10 \mu \mathrm{M}$ (CDK6/7), as against 5.2, 15, 305 and $103 \mathrm{nM}$, respectively, for Flavopiridol [138]. As has been mentioned in the previous sections, due to the high specificity of LDC000067 against CDK9, it has proved to be a valuable tool in pre-clinical studies against multiple and diverse cancer entities $[88,90,94,116]$. However, no clinical trials of LDC000067 were ever undertaken (Table 2).

\subsection{CDKI-73 (LS-007)}

The novel CDK9 inhibitor CDKI-73 was the lead in class compound of a class of 5-substituted 4-(thiazol-5-yl)-2-(phenylamino) pyrimidines, designed by Wang et al., which targeted the ATP gatekeeper residue F30 and ribose-binding pocket of CDK9 [151,152]. Under in vitro conditions, CDKI-73 exhibited IC $_{50}$ of $8.17 \mathrm{nM}$ (CDK1), $3.27 \mathrm{nM}$ (CDK2), $8.18 \mathrm{nM}$ (CDK4), $37.68 \mathrm{nM}$ (CDK6), $134.26 \mathrm{nM}$ (CDK7) and $5.78 \mathrm{nM}$ (CDK9) [153]. Against patient derived CLL cells, CDKI-73 was demonstrated to be significantly more potent than Flavopiridol or its analog Fludarabine. However, when these same cells were protected from the effects of cytotoxic drugs, by culturing them with CD40L-expressing MEFs, CDKI73 retained its cytotoxic effects while that of Fludarabine was completely annulled. It was equally effective against these primary CLL cells $(n=28)$ as against those derived from clinically relapsed CLL patients $(n=10)$, including those harboring p53 deletion $(n=3)$ while exhibiting superior bioavailability than Flavopiridol. Once again, treatment of the primary CLL cells for $4 \mathrm{~h}$ with $0.1 \mu \mathrm{M}$ of CDKI-73 inhibited pS2 and T186 phosphorylations of RNAP II and CDK9, respectively, as well as depleted MCL-1 expression. Interestingly, CDKI-73 demonstrated synergistic cytotoxic effects when combined with Fludarabine, against primary CLL cells, cultured under both normal and cytoprotective conditions [152]. Significantly, CDKI-73 exhibited LD $_{50}$ (median dose of an inhibitor required to kill 50\% of a population within a specified time) values of only $0.08 \mu \mathrm{M}$ (primary CLL cells) as opposed to $40.5 \mu \mathrm{M}$ (normal B-cells) and $23.0 \mu \mathrm{M}$ (normal CD $34^{+}$bone marrow cells), as compared to $\mathrm{LD}_{50}$ of $0.35,0.59$ and $0.52 \mu \mathrm{M}$ for the respective cell types, in the presence of Flavopiridol, demonstrating the excellent safety potential of CDKI-73 [152]. Against AML and ALL cell lines and primary patient derived cells, CDKI-73 and Flavopiridol showed very similar $\mathrm{IC}_{50}\left(163 \mathrm{nM}\right.$ vs. $147 \mathrm{nM}$ ) and $\mathrm{LD}_{50}[67 \mathrm{nM}$ vs. $100 \mathrm{nM}$ (ALL) and $102 \mathrm{nM}$ vs. $112 \mathrm{nM}$ (AML)] values. Ex vivo CDKI-73 inhibited pS2 and pS5 phosphorylations of RNAP II and pT320 phosphorylation of PP1 $\alpha$ at, in a dose-dependent manner, albeit the highest inhibition of pS2 levels, in line with its in vitro $\mathrm{IC}_{50}$ values. CDKI-73 also induced dose- and time-dependent apoptosis in AML and ALL cell lines and patient derived primary cells, as demonstrated by enhanced PARP and Caspase- 3 cleavages and reduced expressions of XIAP and MCL-1 protein and mRNA [153].

Interestingly, in their recent work, Sorvina et al. had demonstrated a novel effect of CDKI-73 in causing the accumulation of large multi-vesicular Rab11 endosomes close to the cell periphery, thereby inhibiting the delivery of the Rab11 vesicles to the plasma membrane. This prevented the trafficking and secretion of anti-microbial peptides like Drosomycin, pro-inflammatory cytokines like IL- 6 and TNF $\alpha$ during an innate immune response. Thus, CDKI-73 could be a potent anti-inflammatory therapy against unwarranted inflammatory response in patients/people with inflammatory disorders [154]. Till date, no clinical studies have been undertaken with CDKI-73. 
Table 2. The various CDK9 inhibitors, their target kinase (s), cancer entities they were tested against (includes pre-clinical trials where clinical trials were never performed) and their clinical trials (wherever performed). Source: www.clinicaltrials. gov (accessed on 12 February 2021).

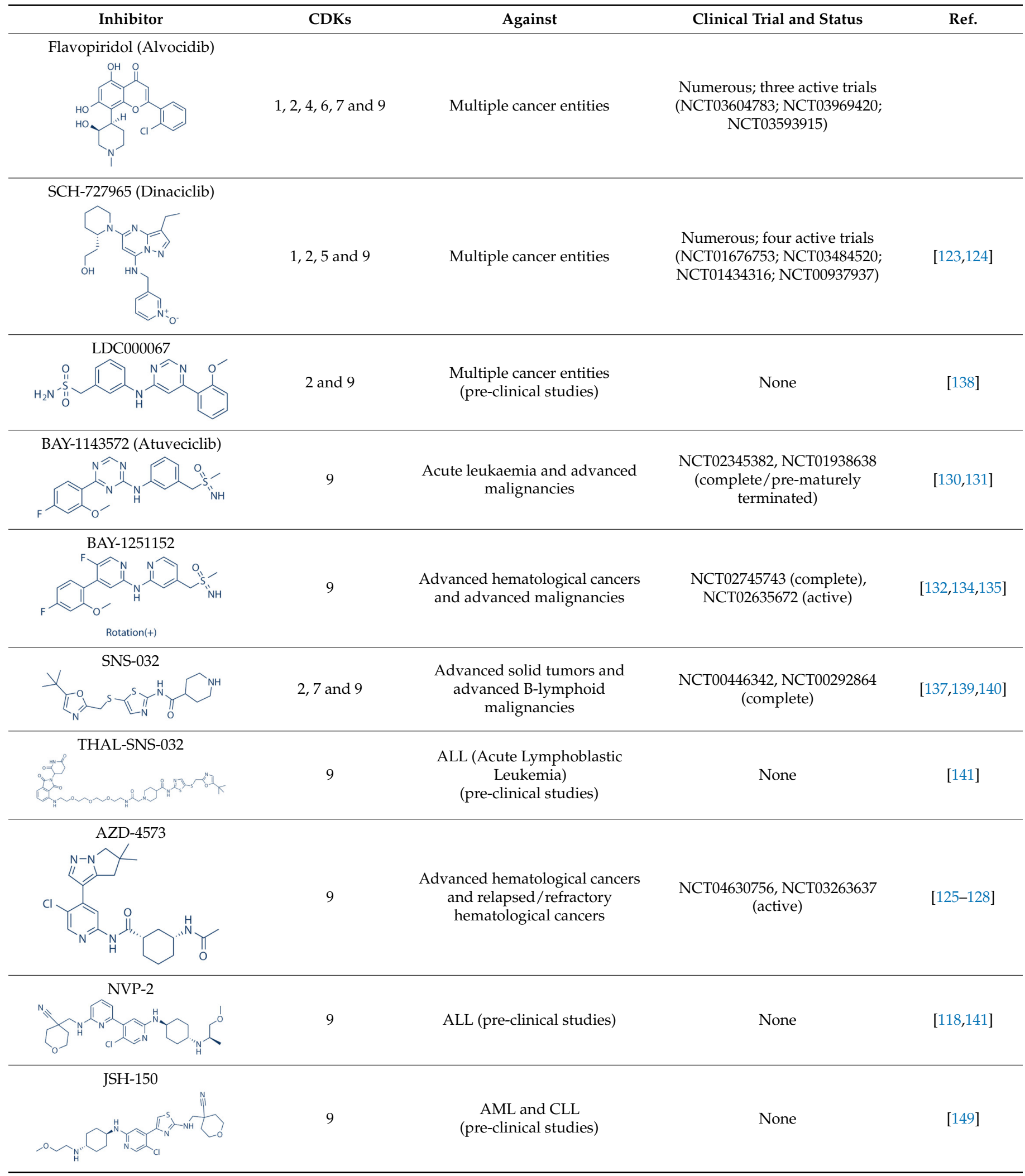


Table 2. Cont.

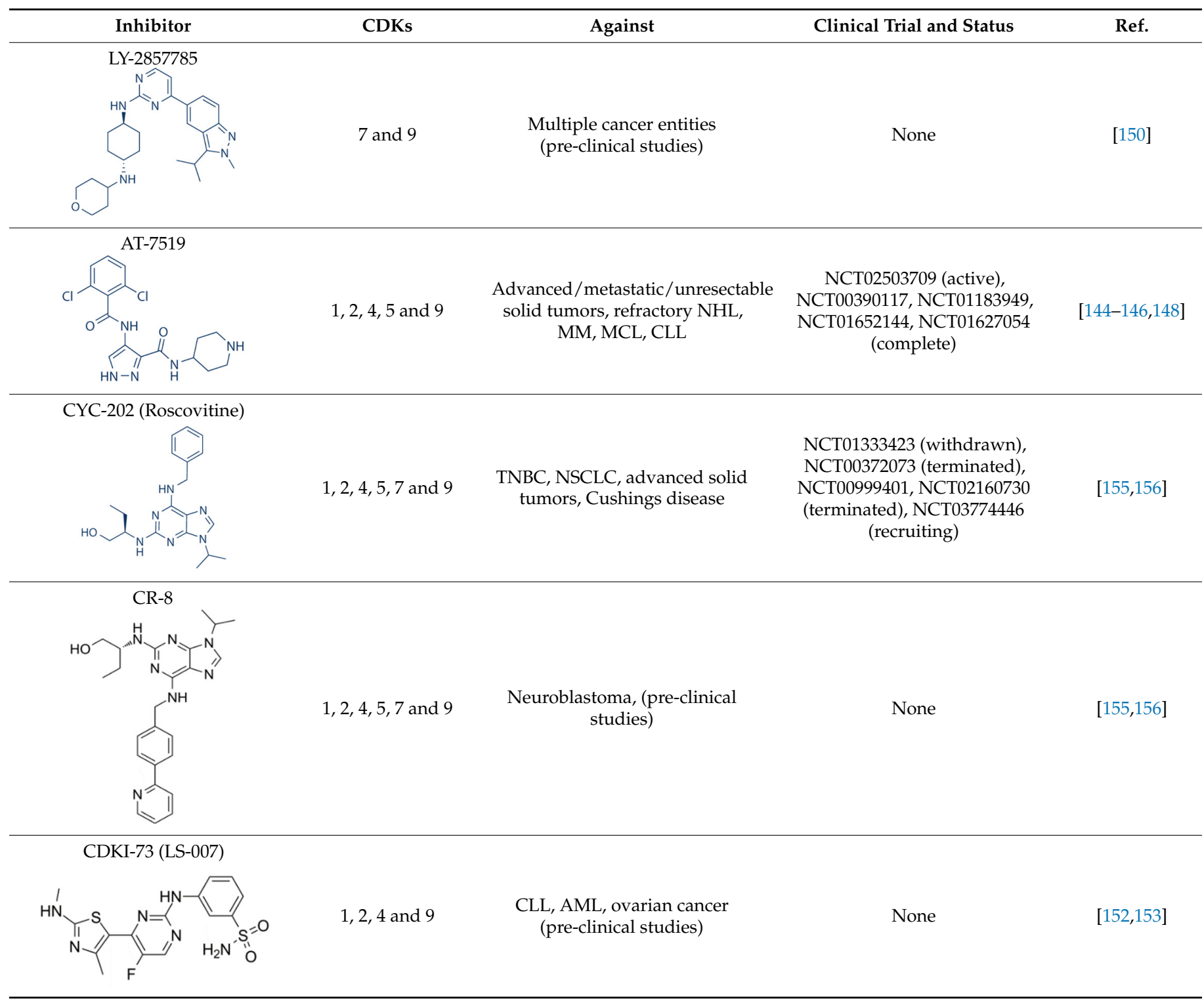

\section{Conclusions}

CDK9 is an extremely critical kinase in regulating the productive transcription of several anti-apoptotic and oncogenic genes, essential for the maintenance, growth, metastasis and chemo-resistance of cancers. In this review, we have only touched upon the proverbial tip of this iceberg. Apart from the cancer entities described here, CDK9 is also involved in many other cancer entities like-pediatric Soft Tissue Sarcomas (STS) like Rhabdomyosarcoma (RMS), Ewing's Sarcoma (ES), Synovial Sarcoma (SS) and Malignant Rhabdoid Tumors (MRT) [1]; Neuroblastoma; Primary Neuroectodermal Tumor (PNET) [157]; cervical cancer [158]; CLL [159]; Glioblastoma [160] etc. The functions of CDK9 is not just limited to cancers, but in other diseases as well like Rheumatoid arthritis [161]; cardiomyocytes development [162]; T-cell activation [163]; replication of viruses like HIV-1 and -2, EBV, CMV, HSV-1 and -2, HTLV-1 [95,164] etc. A great of interest and effort has therefore been invested in targeting the activation of CDK9 or promoting its degradation. As mentioned in our review, many of these inhibitors were put through clinical trials, Flavopiridol being the first of them [149]. Unfortunately, while most of these inhibitors showed promise during pre-clinical trials, many elicited severe side effects or were not effective in generating SD or improving the OS and PFS in patients. Several 
factors can be attributed to these disappointing outcomes like the complex and challenging toxicology profiles of the pan-CDK inhibitors (Table 2) [150] and the critical roles played by CDK9 in the development of normal, surrounding cells. The low numbers of patients with mutations or amplifications in CDK9 for most cancers (Figure 5), a key feature that helped in selectively targeting other kinases like BRAF (Vemurafenib and Dabrafenib against $\mathrm{BRAF}_{\mathrm{V} 600 \mathrm{E}}$ ) and MEK1/2 (Trametinib against $\left.\mathrm{BRAF}_{\mathrm{V} 600 \mathrm{E} / \mathrm{K}}\right)$ specifically in cancer cells $[165,166]$, probably also affected the effectiveness of the next generation inhibitors, which targeted CDK9 far more selectively. Encouragingly enough, during their phase-I clinical trials the 3rd generation inhibitors-BAY-1251152 and AT-7519 had generated generally favorable outcomes involving AML, DLBCL, solid tumors and refractory NHL. AT-7519 was also subjected to two phase-II trials against MCL and CLL [136]. The latest inhibitorAZD-4573 is presently undergoing two phase-I trials against advanced hematological cancers $[127,128]$. These promising recent developments guarantee that the endeavors to target CDK9 activity would undoubtedly continue to be pursued and further refined with newer inhibitors and other strategies, as suggested below.

\section{CDK9 alterations in cancers}

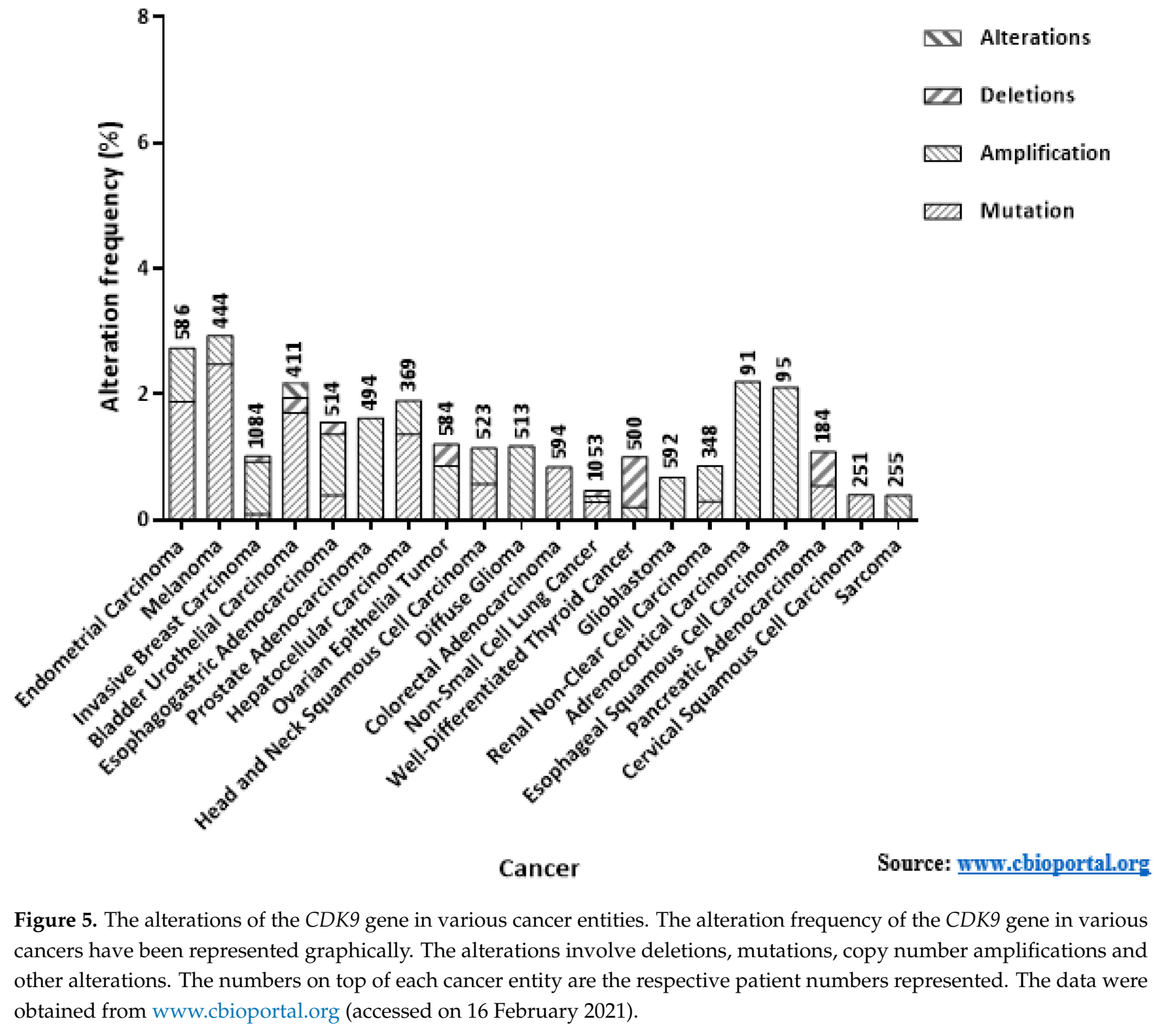


Thus far, most of the clinical trials undertaken with the 2nd and 3rd generation CDK9 inhibitors had been as monotherapies (Table 2). However, one possible way to improve the clinical relevance of these inhibitors is to take advantage of the pathways that regulate the activity of CDK9 and the pathways it in-turn regulates. As explained earlier, BRD4 recruits CDK9 to the promoters [75]. The up-regulation of BRD4 expression is also intimately related with carcinogenesis and poor prognosis [167]. Additionally, unlike CDK9, the genetic alterations of BRD4 also occur with increasing frequencies in different cancer entities (Figure 6A). These reasons have led to the development of a number of inhibitors against BRD4/BET family members [75,167]. Recently, McCalmont et al. had demonstrated the ex and in vivo effects of combining a CDK9 inhibitor and two BET inhibitors. Combinations of CDKI-73 with JQ1 or iBET-151 resulted in the synergistic reduction in cell viability, improved median EFS (Event-Free Survival), as compared to monotherapies against infant ALL and adult AML PDX models harboring the $M L L$-rearrangement ( $M L L-r)$ gene. Significant reduction of leukemic burdens in the bone marrow and spleen were also observed, along with reductions in MYC and BCL-2 protein levels. pS2 levels were also reduced by $49 \%$ with the combination against $29 \%$ with monotherapy. Transcripts of known AML promoting genes-PIM1, HLX, TRAF6 and TRIB3 were also reduced. Only the combination therapy induced significant negative enrichment of transcription factor genes associated with super-enhancers, in the MLL cell line K562 [168]. Another BET inhibitor BI-894999, was also reported to be strongly effective against AML cell lines, patient derived primary materials, and mouse models, more so in combination with LDC000067 in reducing pS2 levels and enhancing apoptosis. Noteworthy, BI-894999 is a part of an active phase $1 \mathrm{a} / \mathrm{b}$ trial against patients with advanced hematological cancers (NCT02516553) [169]. Additionally, combing LDC0000167 with the BRD4 inhibitors-JQ1 or iBET-762 against malignant rhabdoid tumors, down-regulated the anti-apoptotic genes MCL-1, BCL-6 and BTG1 as well as $M Y C$ and inhibited cell-proliferation and tumor growth in vitro and in vivo [170]. Several other BRD4/BET inhibitors like ABBV-075 [171], PLX-51107 [172], CC-90010 and ZEB-3694 are undergoing clinical trials $[173,174]$. Combining BRD4 inhibitors could potentially improve the efficacy of CDK9 inhibitors.

The other reservoir of active P-TEFb-SEC (Figure 3E) has also been targeted recently using the specific inhibitors KL-1 and its structural homolog KL-2, which interfered with association of Cyclin T1 of P-TEFb with the AFF4 subunit of SEC to disrupt the progress of transcription elongation after paused transcription initiation. SEC plays an important role in the transcription of the MYC gene. Likewise, treating the cMYC over-expressing lung cancer cell line H-2171 with either of these two inhibitors resulted in a dose-dependent down-regulation of cell proliferation. In vivo, treating the cMYC-dependent tumor mouse model MDA-231-LM2 with KL-1 or -2 significantly delayed tumor growth and improved the survival of the mice. Apoptosis of the MDA-231-LM2 cells also increased in the presence of the inhibitors $[175,176]$. As mentioned earlier, SEC recruitment required the pre-occupancy of BRD4 $[64,65]$. Therefore, inhibiting CDK9, BRD4 and SEC in combination could prove to be a highly effective trident of inhibitors against cancers, especially against the cMYC driven ones.

Combination of the HSP90 inhibitor Onalespib with the AT-7519 is also undergoing a clinical trial [148]. Other clinical trials of HSP90 inhibitors are also undergoing trials [177] and could be potential combinations with CDK9 inhibitors. As evident from the previous sections, almost all CDK9 inhibitors reduced MCL-1 levels. Therefore, combination of CDK9 inhibitors with those against MCL-1 could also significantly improve the effect of the CDK9 inhibitors. Several such inhibitors are undergoing clinical trials and have been reviewed elsewhere $[178,179]$. Other potential combinations could be with inhibitors of XIAP [180] or BCL-2 [181]. Xie et al. had recently reported that the potent, selective and orally bioavailable BCL-2 inhibitor ABT-199 (Venetoclax), in combination with the potent CDK9 inhibitor CDKI-73 (LS-007) synergistically induced apoptosis in the acute leukemia (AML and ALL) cell lines HL-60, CCRF-CEM and Molt-4, accompanied by increased PARP and Caspase-3 cleavages and reduction in XIAP and MCL-1 expression [153]. Lu et al. 
had recently reported that inhibiting CDK9 activity with their newly developed inhibitor i-CDK9 suppressed phosphorylations of RNAP II at S2 and SPT5 at T775, induced genomewide pausing of RNAP II at gene promoters. Paradoxically, the expressions of MYC and other primary response genes went-up upon sustained i-CDK9 treatment, a potential mechanism of acquired resistance. They had proposed combing the inhibitors of CDK9 with those against BRD4 and CMYC to efficiently inhibit the proliferation and promote apoptosis of cancer cells [182]. MYC is also one of the most frequently altered oncogenes (Figure $6 \mathrm{~B}$ ), being aberrantly expressed in $<70 \%$ of all cancers. Even though initially deemed a difficult target to inhibit, more promising inhibitory strategies against cMYC have been recently developed [183], and could serve as potential combination partners with CDK9 inhibitors. The most promising cancer entities to benefit from inhibiting CDK9, or its up-stream regulators or its down-stream targets would probably be those of leukemic origin as they have clearly defined genetic re-arrangements (like MLL-r) [184] or oncogenic dependence (like $M Y C$ ) $[185,186]$, allowing these cells to be targeted more specifically. Many of the pre- and clinical studies with the CDK9 inhibitors have also been undertaken towards patients with different forms of leukemia (Table 2).

A

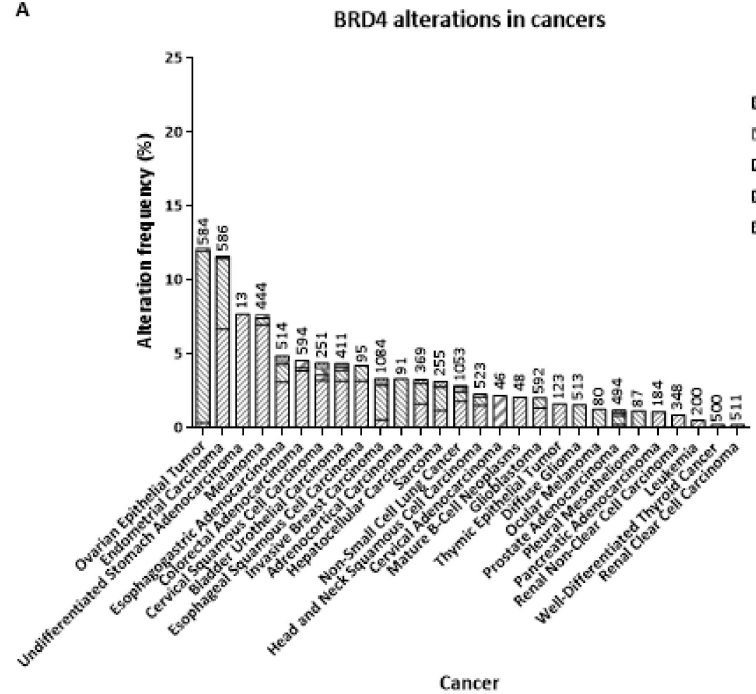

B

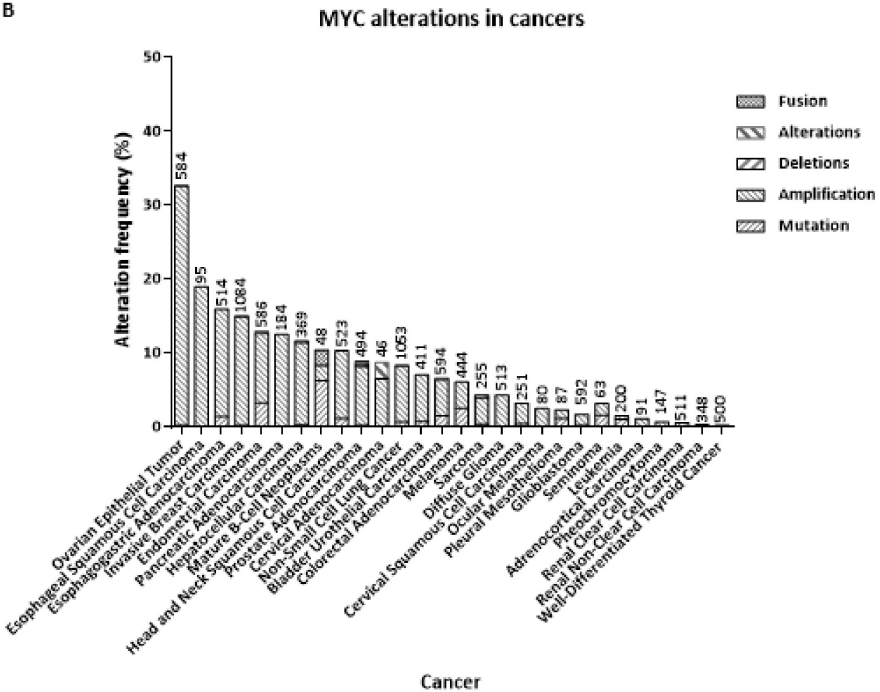

Source: www.cbioportal.org

Figure 6. The alterations of the (A) $B R D 4$ and (B) $M Y C$ genes in various cancer entities. The alteration frequency of the $B R D 4$ and $M Y C$ genes in various cancers have been represented graphically. The alterations involve deletions, mutations, copy number amplifications, other alterations and fusions. The numbers on top of each cancer entity are the respective patient numbers represented. The data were obtained from www.cbioportal.org. (Accessed on 21 February 2021).

In summary, newer generations of CDK9 inhibitors are already opening-up its untapped potential as an anti-cancer therapy and ongoing works in this direction are helping develop better, more selective inhibitors. However, it would be prudent that these CDK9 inhibitors are combined with inhibitors of other proteins/oncogenes/inhibitors of apoptosis/protein complexes like BRD4, SEC, HSP90, cMYC and MCL-1. This would potentially help in- (1) delaying/avoiding potential therapeutic resistance; (2) enhancing the diversity of the treatment regimen; and (3) improving the efficacy of the CDK9 inhibitors. All the above-mentioned inhibitors or inhibition strategies also require to be able to distinguish between normal rapidly proliferating cells like the T-cells and cancer cells. CDKI-73, for example has been reported to have much lower toxicity against T- and B-cells as compared to CLL cells [152,153]. Wogonin, a natural plant-based flavone was shown to target CDK9 activity, in an ATP-competitive manner, resulting in lower pS2 and MCL-1 levels and 
increased apoptosis in CLL and multiple other cancer entities. However, more importantly, Wogonin preferably induced apoptosis in cancer cells over normal cells. Additionally, like CDKI-73, Wogonin and related flavones like Baicalein, Apigenin, Chrysin and Luteolin enhanced the activity of the specific BCL-2 inhibitor ABT-263 in primary AML and ALL cells and cell lines of different cancer entities, while also sensitizing cancer cells harboring acquired ABT-263 resistance $[187,188]$. More exacting pre-clinical trials are necessary to better understand the nuances in the functions of CDK9 between normal and cancer cells, to be able to specifically target the latter.

Funding: This study was funded by Deutsche Forschungsgemeinschaft (DFG) (R. Mandal, Nr.: MA 9266/2-1); Deutsche Krebshilfe (K. Strebhardt, Nr.: 70114007); and German Cancer Consortium (DKTK, Heidelberg).

Conflicts of Interest: The authors declare no conflict of interest.

\section{References}

1. Cassandri, M.; Fioravanti, R.; Pomella, S.; Valente, S.; Rotili, D.; Del Baldo, G.; De Angelis, B.; Rota, R.; Mai, A. CDK9 as a Valuable Target in Cancer: From Natural Compounds Inhibitors to Current Treatment in Pediatric Soft Tissue Sarcomas. Front. Pharmacol. 2020, 11, 1230. [CrossRef] [PubMed]

2. García-Reyes, B.; Kretz, A.-L.; Ruff, J.-P.; Von Karstedt, S.; Hillenbrand, A.; Knippschild, U.; Henne-Bruns, D.; Lemke, J. The Emerging Role of Cyclin-Dependent Kinases (CDKs) in Pancreatic Ductal Adenocarcinoma. Int. J. Mol. Sci. 2018, 19, 3219. [CrossRef] [PubMed]

3. Wood, D.J.; Endicott, J.A. Structural insights into the functional diversity of the CDK-cyclin family. Open Biol. 2018, 8. [CrossRef] [PubMed]

4. Matthess, Y.; Raab, M.; Sanhaji, M.; Lavrik, I.N.; Strebhardt, K. Cdk1/Cyclin B1 Controls Fas-Mediated Apoptosis by Regulating Caspase-8 Activity. Mol. Cell. Biol. 2010, 30, 5726-5740. [CrossRef]

5. Matthess, Y.; Raab, M.; Knecht, R.; Becker, S.; Strebhardt, K. Sequential Cdk1 and Plk1 phosphorylation of caspase-8 triggers apoptotic cell death during mitosis. Mol. Oncol. 2014, 8, 596-608. [CrossRef] [PubMed]

6. Sonawane, Y.A.; Taylor, M.A.; Napoleon, J.V.; Rana, S.; Contreras, J.I.; Natarajan, A. Cyclin Dependent Kinase 9 Inhibitors for Cancer Therapy. J. Med. Chem. 2016, 59, 8667-8684. [CrossRef]

7. O'Leary, B.; Finn, R.S.; Turner, N.C. Treating cancer with selective CDK4/6 inhibitors. Nat. Rev. Clin. Oncol. 2016, 13, 417-430. [CrossRef]

8. Dhavan, R.; Tsai, L.H. A decade of CDK5. Nat. Rev. Clin. Oncol. 2001, 2, 749-759. [CrossRef] [PubMed]

9. Sharma, S.; Sicinski, P. A kinase of many talents: Non-neuronal functions of CDK5 in development and disease. Open Biol. 2020, 10, 190287. [CrossRef]

10. Diab, S.; Yu, M.; Wang, S. CDK7 Inhibitors in Cancer Therapy: The Sweet Smell of Success? J. Med. Chem. 2020, 63, 7458-7474. [CrossRef]

11. Dannappel, M.V.; Sooraj, D.; Loh, J.J.; Firestein, R. Molecular and in vivo Functions of the CDK8 and CDK19 Kinase Modules. Front. Cell Dev. Biol. 2019, 6, 171. [CrossRef]

12. Morales, F.; Giordano, A. Overview of CDK9 as a target in cancer research. Cell Cycle 2016, 15, 519-527. [CrossRef]

13. Guen, V.J.; Gamble, C.; Flajolet, M.; Unger, S.; Thollet, A.; Ferandin, Y.; Superti-Furga, A.; Cohen, P.A.; Meijer, L.; Colas, P. CDK10/cyclin M is a protein kinase that controls ETS2 degradation and is deficient in STAR syndrome. Proc. Natl. Acad. Sci. USA 2013, 110, 19525-19530. [CrossRef]

14. Robert, T.; Johnson, J.L.; Guichaoua, R.; Yaron, T.M.; Bach, S.; Cantley, L.C.; Colas, P. Development of a CDK10/CycM in vitro Kinase Screening Assay and Identification of First Small-Molecule Inhibitors. Front. Chem. 2020, 8, 147. [CrossRef]

15. Bösken, C.A.; Farnung, L.; Hintermair, C.; Schachter, M.M.; Vogel-Bachmayr, K.; Blazek, D.; Anand, K.; Fisher, R.P.; Eick, D.; Geyer, M. The structure and substrate specificity of human Cdk12/Cyclin K. Nat. Commun. 2014, 5, 3505. [CrossRef] [PubMed]

16. Pilarova, K.; Herudek, J.; Blazek, D. CDK12: Cellular functions and therapeutic potential of versatile player in cancer. NAR Cancer 2020, 2. [CrossRef]

17. Fan, Z.; Devlin, J.R.; Hogg, S.J.; Doyle, M.A.; Harrison, P.F.; Todorovski, I.; Cluse, L.A.; Knight, D.A.; Sandow, J.J.; Gregory, G.; et al. CDK13 cooperates with CDK12 to control global RNA polymerase II processivity. Sci. Adv. 2020, 6, eaaz5041. [CrossRef] [PubMed]

18. Li, S.; Song, W.; Jiang, M.; Zeng, L.; Zhu, X.; Chen, J. Phosphorylation of cyclin Y by CDK14 induces its ubiquitination and degradation. FEBS Lett. 2014, 588, 1989-1996. [CrossRef]

19. Park, M.H.; Kim, S.Y.; Kim, Y.J.; Chung, Y.-H. ALS2CR7 (CDK15) attenuates TRAIL induced apoptosis by inducing phosphorylation of survivin Thr34. Biochem. Biophys. Res. Commun. 2014, 450, 129-134. [CrossRef]

20. Mikolcevic, P.; Sigl, R.; Rauch, V.; Hess, M.W.; Pfaller, K.; Barisic, M.; Pelliniemi, L.J.; Boesl, M.; Geley, S. Cyclin-Dependent Kinase 16/PCTAIRE Kinase 1 Is Activated by Cyclin Y and Is Essential for Spermatogenesis. Mol. Cell. Biol. 2011, 32, 868-879. [CrossRef] 
21. Wang, H.; Liu, H.; Min, S.; Shen, Y.; Li, W.; Chen, Y.; Wang, X. CDK16 overexpressed in non-small cell lung cancer and regulates cancer cell growth and apoptosis via a p27-dependent mechanism. Biomed. Pharmacother. 2018, 103, 399-405. [CrossRef]

22. Dixon-Clarke, S.E.; Shehata, S.N.; Krojer, T.; Sharpe, T.D.; Von Delft, F.; Sakamoto, K.; Bullock, A.N. Structure and inhibitor specificity of the PCTAIRE-family kinase CDK16. Biochem. J. 2017, 474, 699-713. [CrossRef] [PubMed]

23. Axtman, A.; Drewry, D.; Wells, C. CDK16: The pick of the understudied PCTAIRE kinases. Nat. Rev. Drug Discov. 2019, 18, 489. [CrossRef]

24. Braams, E.; D'Angiolella, V. Keeping CDK18 in balance to prevent DNA replication stress in breast cancer. Oncotarget 2018, 9 , 37610-37611. [CrossRef]

25. Matsuda, S.; Kawamoto, K.; Miyamoto, K.; Tsuji, A.; Yuasa, K. PCTK3/CDK18 regulates cell migration and adhesion by negatively modulating FAK activity. Sci. Rep. 2017, 7, 45545. [CrossRef]

26. Barone, G.; Staples, C.J.; Ganesh, A.; Patterson, K.W.; Bryne, D.P.; Myers, K.N.; Patil, A.A.; Eyers, C.E.; Maslen, S.; Skehel, J.M.; et al. Human CDK18 promotes replication stress signaling and genome stability. Nucleic Acids Res. 2016, 44, 8772-8785. [CrossRef] [PubMed]

27. Lai, L.; Shin, G.Y.; Qiu, H. The Role of Cell Cycle Regulators in Cell Survival—Dual Functions of Cyclin-Dependent Kinase 20

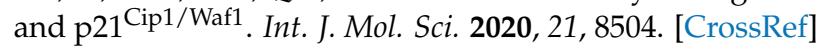

28. Webster, K.A.; Henke, K.; Ingalls, D.M.; Nahrin, A.; Harris, M.P.; Siegfried, K.R. Cyclin-dependent kinase 21 is a novel regulator of proliferation and meiosis in the male germline of zebrafish. Reproduction 2019, 157, 383-398. [CrossRef]

29. Grana, X.; De Luca, A.; Sang, N.; Fu, Y.; Claudio, P.P.; Rosenblatt, J.; Morgan, D.O.; Giordano, A. PITALRE, a nuclear CDC2-related protein kinase that phosphorylates the retinoblastoma protein in vitro. Proc. Natl. Acad. Sci. USA 1994, 91, 3834-3838. [CrossRef]

30. Paparidis, N.F.D.S.; Durvale, M.C.; Canduri, F. The emerging picture of CDK9/P-TEFb: More than 20 years of advances since PITALRE. Mol. BioSyst. 2017, 13, 246-276. [CrossRef]

31. Shore, S.M.; Byers, S.A.; Maury, W.; Price, D.H. Identification of a novel isoform of Cdk9. Gene 2003, 307, 175-182. [CrossRef]

32. Baumli, S.; Lolli, G.; Lowe, E.D.; Troiani, S.; Rusconi, L.; Bullock, A.N.; Debreczeni, J.É; Knapp, S.; Johnson, L.N. The structure of P-TEFb (CDK9/cyclin T1), its complex with flavopiridol and regulation by phosphorylation. EMBO J. 2008, 27, 1907-1918. [CrossRef]

33. Ramakrishnan, R.; Yu, W.; Rice, A.P. Limited redundancy in genes regulated by Cyclin T2 and Cyclin T1. BMC Res. Notes 2011, 4, 260. [CrossRef] [PubMed]

34. Edwards, M.C.; Wong, C.; Elledge, S.J. Human Cyclin K, a Novel RNA Polymerase II-Associated Cyclin Possessing Both Carboxy-Terminal Domain Kinase and Cdk-Activating Kinase Activity. Mol. Cell. Biol. 1998, 18, 4291-4300. [CrossRef]

35. Blazek, D. The cyclin K/Cdk12 complex: An emerging new player in the maintenance of genome stability. Cell Cycle 2012, 11, 1049-1050. [CrossRef]

36. Kohoutek, J.; Blazek, D. Cyclin K goes with Cdk12 and Cdk13. Cell Div. 2012, 7, 12. [CrossRef]

37. LaRochelle, S.; Amat, R.; Glover-Cutter, K.; Sansó, M.; Zhang, C.; Allen, J.J.; Shokat, K.M.; Bentley, D.L.; Fisher, R.P. Cyclindependent kinase control of the initiation-to-elongation switch of RNA polymerase II. Nat. Struct. Mol. Biol. 2012, 19, 1108-1115. [CrossRef]

38. Mbonye, U.; Wang, B.; Gokulrangan, G.; Shi, W.; Yang, S.; Karn, J. Cyclin-dependent kinase 7 (CDK7)-mediated phosphorylation of the CDK9 activation loop promotes P-TEFb assembly with Tat and proviral HIV reactivation. J. Biol. Chem. 2018, 293, 10009-10025. [CrossRef]

39. Mbonye, U.R.; Gokulrangan, G.; Datt, M.; Dobrowolski, C.; Cooper, M.; Chance, M.R.; Karn, J. Phosphorylation of CDK9 at Ser175 Enhances HIV Transcription and Is a Marker of Activated P-TEFb in CD4+ T Lymphocytes. PLOS Pathog. 2013, 9, e1003338. [CrossRef]

40. Nekhai, S.; Petukhov, M.; Breuer, D. Regulation of CDK9 Activity by Phosphorylation and Dephosphorylation. BioMed Res. Int. 2014, 2014, 1-8. [CrossRef]

41. Ramakrishnan, R.; Rice, A.P. Cdk9 T-loop phosphorylation is regulated by the calcium signaling pathway. J. Cell. Physiol. 2011, 227, 609-617. [CrossRef] [PubMed]

42. Kim, J.B.; Sharp, P.A. Positive Transcription Elongation Factor b Phosphorylates hSPT5 and RNA Polymerase II Carboxyl-terminal Domain Independently of Cyclin-dependent Kinase-activating Kinase. J. Biol. Chem. 2001, 276, 12317-12323. [CrossRef] [PubMed]

43. Grünberg, S.; Hahn, S. Structural insights into transcription initiation by RNA polymerase II. Trends Biochem. Sci. 2013, 38, 603-611. [CrossRef]

44. Sainsbury, S.; Bernecky, C.; Cramer, P. Structural basis of transcription initiation by RNA polymerase II. Nat. Rev. Mol. Cell Biol. 2015, 16, 129-143. [CrossRef]

45. Chen, F.X.; Smith, E.R.; Shilatifard, A. Born to run: Control of transcription elongation by RNA polymerase II. Nat. Rev. Mol. Cell Biol. 2018, 19, 464-478. [CrossRef] [PubMed]

46. Greber, B.J.; Toso, D.B.; Fang, J.; Nogales, E. Author response: The complete structure of the human TFIIH core complex. Elife 2019, 8, e44771. [CrossRef] [PubMed]

47. Kohoutek, J. P-TEFb- the final frontier. Cell Div. 2009, 4, 19. [CrossRef]

48. Compe, E.; Egly, J.M. TFIIH: When transcription met DNA repair. Nat. Rev. Mol. Cell Biol. 2012, 13, 343-354. [CrossRef]

49. Peterlin, B.M.; Price, D.H. Controlling the Elongation Phase of Transcription with P-TEFb. Mol. Cell 2006, 23, 297-305. [CrossRef]

50. Zhou, Q.; Li, T.; Price, D.H. RNA Polymerase II Elongation Control. Annu. Rev. Biochem. 2012, 81, 119-143. [CrossRef] [PubMed] 
51. Brannan, K.; Kim, H.; Erickson, B.; Glover-Cutter, K.; Kim, S.; Fong, N.; Kiemele, L.; Hansen, K.; Davis, R.; Lykke-Andersen, J.; et al. mRNA Decapping Factors and the Exonuclease Xrn2 Function in Widespread Premature Termination of RNA Polymerase II Transcription. Mol. Cell 2012, 46, 311-324. [CrossRef]

52. Henriques, T.; Gilchrist, D.A.; Nechaev, S.; Bern, M.; Muse, G.W.; Burkholder, A.; Fargo, D.C.; Adelman, K. Stable Pausing by RNA Polymerase II Provides an Opportunity to Target and Integrate Regulatory Signals. Mol. Cell 2013, 52, 517-528. [CrossRef] [PubMed]

53. Garriga, J.; Graña, X. CDK9 inhibition strategy defines distinct sets of target genes. BMC Res. Notes 2014, 7, 301. [CrossRef]

54. Baumli, S.; Furst, R. Perspective of Cyclin-dependent kinase 9 (CDK9) as a Drug Target. Curr. Pharm. Des. 2012, 18, 2883-2890. [CrossRef]

55. Feinberg, M.B.; Baltimore, D.; Frankel, A.D. The role of Tat in the human immunodeficiency virus life cycle indicates a primary effect on transcriptional elongation. Proc. Natl. Acad. Sci. 1991, 88, 4045-4049. [CrossRef] [PubMed]

56. Chiu, Y.-L.; Cao, H.; Jacque, J.-M.; Stevenson, M.; Rana, T.M. Inhibition of Human Immunodeficiency Virus Type 1 Replication by RNA Interference Directed against Human Transcription Elongation Factor P-TEFb (CDK9/CyclinT1). J. Virol. 2004, 78, 2517-2529. [CrossRef]

57. Garber, M.E.; Mayall, T.P.; Suess, E.M.; Meisenhelder, J.; Thompson, N.E.; Jones, K.A. CDK9 Autophosphorylation Regulates High-Affinity Binding of the Human Immunodeficiency Virus Type 1 Tat-P-TEFb Complex to TAR RNA. Mol. Cell. Biol. 2000, 20, 6958-6969. [CrossRef]

58. Wei, P.; Garber, M.E.; Fang, S.-M.; Fischer, W.H.; Jones, K.A. A Novel CDK9-Associated C-Type Cyclin Interacts Directly with HIV-1 Tat and Mediates Its High-Affinity, Loop-Specific Binding to TAR RNA. Cell 1998, 92, 451-462. [CrossRef]

59. Peng, J.; Zhu, Y.; Milton, J.T.; Price, D.H. Identification of multiple cyclin subunits of human P-TEFb. Genes Dev. 1998, 12, 755-762. [CrossRef]

60. Yamada, T.; Yamaguchi, Y.; Inukai, N.; Okamoto, S.; Mura, T.; Handa, H. P-TEFb-Mediated Phosphorylation of hSpt5 C-Terminal Repeats Is Critical for Processive Transcription Elongation. Mol. Cell 2006, 21, 227-237. [CrossRef]

61. Bowman, E.A.; Kelly, W.G. RNA polymerase II transcription elongation and Pol II CTD Ser2 phosphorylation: A tail of two kinases. Nucleus 2014, 5, 224-236. [CrossRef]

62. Patel, A.B.; Louder, R.K.; Greber, B.J.; Grünberg, S.; Luo, J.; Fang, J.; Liu, Y.; Ranish, J.; Hahn, S.; Nogales, E. Structure of human TFIID and mechanism of TBP loading onto promoter DNA. Science 2018, 362, eaau8872. [CrossRef]

63. Soutourina, J. Transcription regulation by the Mediator complex. Nat. Rev. Mol. Cell Biol. 2018, 19, 262-274. [CrossRef]

64. He, N.; Chan, C.K.; Sobhian, B.; Chou, S.; Xue, Y.; Liu, M.; Alber, T.; Benkirane, M.; Zhou, Q. Human Polymerase-Associated Factor complex (PAFc) connects the Super Elongation Complex (SEC) to RNA polymerase II on chromatin. Proc. Natl. Acad. Sci. USA 2011, 108, E636-E645. [CrossRef]

65. Luo, Z.; Lin, C.; Shilatifard, A. The super elongation complex (SEC) family in transcriptional control. Nat. Rev. Mol. Cell Biol. 2012, 13, 543-547. [CrossRef]

66. Nguyen, V.T.; Kiss, T.; Michels, A.A.; Bensaude, O. 7SK small nuclear RNA binds to and inhibits the activity of CDK9/cyclin T complexes. Nat. Cell Biol. 2001, 414, 322-325. [CrossRef]

67. Yang, Z.; Zhu, Q.; Luo, K.; Zhou, Q. The 7SK small nuclear RNA inhibits the CDK9/cyclin T1 kinase to control transcription. Nat. Cell Biol. 2001, 414, 317-322. [CrossRef]

68. Quaresma, A.J.C.; Bugai, A.; Barboric, M. Cracking the control of RNA polymerase II elongation by 7SK snRNP and P-TEFb. Nucleic Acids Res. 2016, 44, 7527-7539. [CrossRef] [PubMed]

69. Michels, A.A.; Fraldi, A.; Li, Q.; Adamson, T.E.; Bonnet, F.; Nguyen, V.T.; Sedore, S.C.; Price, J.P.; Price, D.H.; Lania, L.; et al. Binding of the 7SK snRNA turns the HEXIM1 protein into a P-TEFb (CDK9/cyclin T) inhibitor. EMBO J. 2004, 23, 2608-2619. [CrossRef]

70. Krueger, B.J.; Jeronimo, C.; Roy, B.B.; Bouchard, A.; Barrandon, C.; Byers, S.A.; Searcey, C.E.; Cooper, J.J.; Bensaude, O.; Cohen, É.A.; et al. LARP7 is a stable component of the 7SK snRNP while P-TEFb, HEXIM1 and hnRNP A1 are reversibly associated. Nucleic Acids Res. 2008, 36, 2219-2229. [CrossRef]

71. Markert, A.; Grimm, M.; Martinez, J.; Wiesner, J.; Meyerhans, A.; Meyuhas, O.; Sickmann, A.; Fischer, U. The La-related protein LARP7 is a component of the 7SK ribonucleoprotein and affects transcription of cellular and viral polymerase II genes. EMBO Rep. 2008, 9, 569-575. [CrossRef]

72. Jeronimo, C.; Forget, D.; Bouchard, A.; Li, Q.; Chua, G.; Poitras, C.; Thérien, C.; Bergeron, D.; Bourassa, S.; Greenblatt, J.; et al. Systematic Analysis of the Protein Interaction Network for the Human Transcription Machinery Reveals the Identity of the 7SK Capping Enzyme. Mol. Cell 2007, 27, 262-274. [CrossRef] [PubMed]

73. Xue, Y.; Yang, Z.; Chen, R.; Zhou, Q. A capping-independent function of MePCE in stabilizing 7SK snRNA and facilitating the assembly of 7SK snRNP. Nucleic Acids Res. 2009, 38, 360-369. [CrossRef]

74. Chen, R.; Yang, Z.; Zhou, Q. Phosphorylated Positive Transcription Elongation Factor b (P-TEFb) Is Tagged for Inhibition through Association with 7SK snRNA. J. Biol. Chem. 2004, 279, 4153-4160. [CrossRef]

75. Donati, B.; Lorenzini, E.; Ciarrocchi, A. BRD4 and Cancer: Going beyond transcriptional regulation. Mol. Cancer 2018, 17, 1-13. [CrossRef]

76. Filippakopoulos, P.; Picaud, S.; Mangos, M.; Keates, T.; Lambert, J.-P.; Barsyte-Lovejoy, D.; Felletar, I.; Volkmer, R.; Müller, S.; Pawson, T.; et al. Histone Recognition and Large-Scale Structural Analysis of the Human Bromodomain Family. Cell 2012, 149, 214-231. [CrossRef] 
77. Vollmuth, F.; Blankenfeldt, W.; Geyer, M. Structures of the Dual Bromodomains of the P-TEFb-activating Protein Brd4 at Atomic Resolution. J. Biol. Chem. 2009, 284, 36547-36556. [CrossRef] [PubMed]

78. Zhou, M.; Huang, K.; Jung, K.-J.; Cho, W.-K.; Klase, Z.; Kashanchi, F.; Pise-Masison, C.A.; Brady, J.N. Bromodomain Protein Brd4 Regulates Human Immunodeficiency Virus Transcription through Phosphorylation of CDK9 at Threonine 29. J. Virol. 2008, 83, 1036-1044. [CrossRef]

79. Schröder, S.; Cho, S.; Zeng, L.; Zhang, Q.; Kaehlcke, K.; Mak, L.; Lau, J.; Bisgrove, D.; Schnölzer, M.; Verdin, E.; et al. Twopronged Binding with Bromodomain-containing Protein 4 Liberates Positive Transcription Elongation Factor $b$ from Inactive Ribonucleoprotein Complexes*. J. Biol. Chem. 2012, 287, 1090-1099. [CrossRef]

80. Itzen, F.; Greifenberg, A.K.; Bösken, C.A.; Geyer, M. Brd4 activates P-TEFb for RNA polymerase II CTD phosphorylation. Nucleic Acids Res. 2014, 42, 7577-7590. [CrossRef]

81. Yang, Z.; Yik, J.H.N.; Chen, R.; He, N.; Jang, M.K.; Ozato, K.; Zhou, Q. Recruitment of P-TEFb for Stimulation of Transcriptional Elongation by the Bromodomain Protein Brd4. Mol. Cell 2005, 19, 535-545. [CrossRef]

82. Michels, A.A.; Bensaude, O. Hexim1, an RNA-controlled protein hub. Transcription 2018, 9, 262-271. [CrossRef] [PubMed]

83. O'Keeffe, B.; Fong, Y.; Chen, D.; Zhou, S.; Zhou, Q. Requirement for a Kinase-specific Chaperone Pathway in the Production of a Cdk9/Cyclin T1 Heterodimer Responsible for P-TEFb-mediated Tat Stimulation of HIV-1 Transcription. J. Biol. Chem. 2000, 275, 279-287. [CrossRef]

84. Kostova, I.; Mandal, R.; Becker, S.; Strebhardt, K. The role of caspase-8 in the tumor microenvironment of ovarian cancer. Cancer Metastasis Rev. 2021, 40, 303-318. [CrossRef] [PubMed]

85. Mandal, R.; Barrón, J.C.; Kostova, I.; Becker, S.; Strebhardt, K. Caspase-8: The double-edged sword. Biochim. Biophys. Acta Rev. Cancer 2020, 1873, 188357. [CrossRef]

86. Napolitano, G.; Licciardo, P.; Carbone, R.; Majello, B.; Lania, L. CDK9 has the intrinsic property to shuttle between nucleus and cytoplasm, and enhanced expression of CyclinT1 promotes its nuclear localization. J. Cell. Physiol. 2002, 192, 209-215. [CrossRef]

87. Brasier, A.R. Perspective: Expanding role of cyclin dependent kinases in cytokine inducible gene expression. Cell Cycle 2008, 7 , 2661-2666. [CrossRef]

88. Ma, H.; Seebacher, N.A.; Hornicek, F.J.; Duan, Z. Cyclin-dependent kinase 9 (CDK9) is a novel prognostic marker and therapeutic target in osteosarcoma. EBioMedicine 2019, 39, 182-193. [CrossRef]

89. Sengupta, S.; Biarnes, M.C.; Jordan, V.C. Cyclin dependent kinase-9 mediated transcriptional de-regulation of cMYC as a critical determinant of endocrine-therapy resistance in breast cancers. Breast Cancer Res. Treat. 2014, 143, 113-124. [CrossRef]

90. He, S.; Fang, X.; Xia, X.; Hou, T.; Zhang, T. Targeting CDK9: A novel biomarker in the treatment of endometrial cancer. Oncol. Rep. 2020, 44, 1929-1938. [CrossRef]

91. Boffo, S.; Damato, A.; Alfano, L.; Giordano, A.; Alfano, L. CDK9 inhibitors in acute myeloid leukemia. J. Exp. Clin. Cancer Res. 2018, 37, 1-10. [CrossRef]

92. Strebhardt, K.; Ullrich, A. Paul Ehrlich's magic bullet concept: 100 years of progress. Nat. Rev. Cancer 2008, 8, 473-480. [CrossRef] [PubMed]

93. McNeil, C.M.; Sergio, C.M.; Anderson, L.R.; Inman, C.K.; Eggleton, S.A.; Murphy, N.C.; Millar, E.K.; Crea, P.; Kench, J.G.; Alles, M.C.; et al. c-Myc overexpression and endocrine resistance in breast cancer. J. Steroid Biochem. Mol. Biol. 2006, 102, $147-155$. [CrossRef] [PubMed]

94. Qin, J.-J. Is CDK9 a promising target for both primary and metastatic osteosarcoma? EBioMedicine 2019, 40, 27-28. [CrossRef]

95. Franco, L.C.; Morales, F.; Boffo, S.; Giordano, A. CDK9: A key player in cancer and other diseases. J. Cell. Biochem. 2018, 119, 1273-1284. [CrossRef] [PubMed]

96. Lyle, L.; Daver, N. Current and emerging therapies for patients with acute myeloid leukemia: A focus on MCL-1 and the CDK9 pathway. Am. J. Manag. Care 2018, 24, S356-S365.

97. Lee, D.J.; Zeidner, J.F. Cyclin-dependent kinase (CDK) 9 and 4/6 inhibitors in acute myeloid leukemia (AML): A promising therapeutic approach. Expert Opin. Investig. Drugs 2019, 28, 989-1001. [CrossRef]

98. Bogenberger, J.; Whatcott, C.; Hansen, N.; Delman, D.; Shi, C.-X.; Kim, W.; Haws, H.; Soh, K.; Lee, Y.S.; Peterson, P.; et al. Combined venetoclax and alvocidib in acute myeloid leukemia. Oncotarget 2017, 8, 107206-107222. [CrossRef]

99. Devaraj, S.G.T.; Fiskus, W.; Shah, B.A.; Qi, J.; Sun, B.; Iyer, S.P.; Sharma, S.; Bradner, J.E.; Bhalla, K.N. HEXIM1 induction is mechanistically involved in mediating anti-AML activity of BET protein bromodomain antagonist. Leukemia 2016, 30, 504-508. [CrossRef]

100. Lew, Q.J.; Chu, K.L.; Chia, Y.L.; Cheong, N.; Chao, S.-H. HEXIM1, a New Player in the p53 Pathway. Cancers 2013, 5, 838-856. [CrossRef]

101. Kalluri, R. Basement membranes: Structure, assembly and role in tumour angiogenesis. Nat. Rev. Cancer 2003, 3, $422-433$. [CrossRef]

102. Friedl, P.; Wolf, K. Tumour-cell invasion and migration: Diversity and escape mechanisms. Nat. Rev. Cancer 2003, 3, 362-374. [CrossRef]

103. Shan, B.; Zhuo, Y.; Chin, D.; Morris, C.A.; Morris, G.F.; Lasky, J.A. Cyclin-dependent Kinase 9 Is Required for Tumor Necrosis Factor- $\alpha$-stimulated Matrix Metalloproteinase-9 Expression in Human Lung Adenocarcinoma Cells. J. Biol. Chem. 2005, 280, 1103-1111. [CrossRef] 
104. Wang, X.; Yu, C.; Wang, C.; Ma, Y.; Wang, T.; Li, Y.; Huang, Z.; Zhou, M.; Sun, P.; Zheng, J.; et al. Novel cyclin-dependent kinase 9 (CDK9) inhibitor with suppression of cancer stemness activity against non-small-cell lung cancer. Eur. J. Med. Chem. 2019, 181, 111535. [CrossRef] [PubMed]

105. Fujita, K.; Nonomura, N. Role of Androgen Receptor in Prostate Cancer: A Review. World J. Men's Health 2019, 37, $288-295$. [CrossRef]

106. Rahaman, M.H.; Kumarasiri, M.; Mekonnen, L.B.; Yu, M.; Diab, S.; Albrecht, H.; Milne, R.W.; Wang, S. Targeting CDK9: A promising therapeutic opportunity in prostate cancer. Endocr. Relat. Cancer 2016, 23, T211-T226. [CrossRef]

107. Chen, S.; Gulla, S.; Cai, C.; Balk, S.P. Androgen Receptor Serine 81 Phosphorylation Mediates Chromatin Binding and Transcriptional Activation. J. Biol. Chem. 2012, 287, 8571-8583. [CrossRef]

108. Chen, S.; Xu, Y.; Yuan, X.; Bubley, G.J.; Balk, S.P. Androgen receptor phosphorylation and stabilization in prostate cancer by cyclin-dependent kinase 1. Proc. Natl. Acad. Sci. USA 2006, 103, 15969-15974. [CrossRef]

109. Hsu, F.-N.; Chen, M.-C.; Chiang, M.-C.; Lin, E.; Lee, Y.-T.; Huang, P.-H.; Lee, G.-S.; Lin, H. Regulation of Androgen Receptor and Prostate Cancer Growth by Cyclin-dependent Kinase 5. J. Biol. Chem. 2011, 286, 33141-33149. [CrossRef]

110. Gordon, V.; Bhadel, S.; Wunderlich, W.; Zhang, J.; Ficarro, S.B.; Mollah, S.A.; Shabanowitz, J.; Hunt, D.F.; Xenarios, I.; Hahn, W.C.; et al. CDK9 Regulates AR Promoter Selectivity and Cell Growth through Serine 81 Phosphorylation. Mol. Endocrinol. 2010, 24, 2267-2280. [CrossRef]

111. Abdullah, C.; Wang, X.; Becker, D. Expression analysis and molecular targeting of cyclin-dependent kinases in advanced melanoma. Cell Cycle 2011, 10, 977-988. [CrossRef]

112. Zhang, J.; Liu, S.; Ye, Q.; Pan, J. Transcriptional inhibition by CDK7/9 inhibitor SNS-032 abrogates oncogene addiction and reduces liver metastasis in uveal melanoma. Mol. Cancer 2019, 18, 140. [CrossRef]

113. Zhang, Y.; Hou, J.; Shi, S.; Du, J.; Liu, Y.; Huang, P.; Li, Q.; Liu, L.; Hu, H.; Ji, Y.; et al. CSN6 promotes melanoma proliferation and metastasis by controlling the UBR5-mediated ubiquitination and degradation of CDK9. Cell Death Dis. 2021, 12, 1-12. [CrossRef]

114. Fang, L.; Lu, W.; Choi, H.H.; Yeung, S.-C.J.; Tung, J.-Y.; Hsiao, C.-D.; Fuentes-Mattei, E.; Menter, D.; Chen, C.; Wang, L.; et al. ERK2-Dependent Phosphorylation of CSN6 Is Critical in Colorectal Cancer Development. Cancer Cell 2015, 28, 183-197. [CrossRef]

115. Gao, S.; Fang, L.; Phan, L.M.; Qdaisat, A.; Yeung, S.-C.J.; Lee, M.-H. COP9 signalosome subunit 6 (CSN6) regulates E6AP/UBE3A in cervical cancer. Oncotarget 2015, 6, 28026-28041. [CrossRef]

116. Wang, J.; Dean, D.C.; Hornicek, F.J.; Shi, H.; Duan, Z. Cyclin-dependent kinase 9 (CDK9) is a novel prognostic marker and therapeutic target in ovarian cancer. FASEB J. 2019, 33, 5990-6000. [CrossRef]

117. Kumara, P.M.; Soujanya, K.; Ravikanth, G.; Vasudeva, R.; Ganeshaiah, K.; Shaanker, R.U. Rohitukine, a chromone alkaloid and a precursor of flavopiridol, is produced by endophytic fungi isolated from Dysoxylum binectariferum Hook.f and Amoora rohituka (Roxb).Wight \& Arn. Phytomedicine 2014, 21, 541-546. [CrossRef] [PubMed]

118. Galbraith, M.D.; Bender, H.; Espinosa, J.M. Therapeutic targeting of transcriptional cyclin-dependent kinases. Transcription 2019, 10, 118-136. [CrossRef] [PubMed]

119. Weinstein, J.N.; Myers, T.G.; O'Connor, P.M.; Friend, S.H.; Fornace, A.J.; Kohn, K.W.; Fojo, T.; Bates, S.E.; Rubinstein, L.V.; Anderson, N.L.; et al. An Information-Intensive Approach to the Molecular Pharmacology of Cancer. Science 1997, 275, 343-349. [CrossRef] [PubMed]

120. Senderowicz, A.M. Flavopiridol: The First Cyclin-Dependent Kinase Inhibitor in Human Clinical Trials. Investig. New Drugs 1999, 17, 313-320. [CrossRef]

121. Chao, S.-H.; Price, D.H. Flavopiridol Inactivates P-TEFb and Blocks Most RNA Polymerase II Transcription in Vivo. J. Biol. Chem. 2001, 276, 31793-31799. [CrossRef] [PubMed]

122. Chou, J.; Quigley, D.A.; Robinson, T.M.; Feng, F.Y.; Ashworth, A. Transcription-Associated Cyclin-Dependent Kinases as Targets and Biomarkers for Cancer Therapy. Cancer Discov. 2020, 10, 351-370. [CrossRef] [PubMed]

123. Parry, D.; Guzi, T.; Shanahan, F.; Davis, N.; Prabhavalkar, D.; Wiswell, D.; Seghezzi, W.; Paruch, K.; Dwyer, M.P.; Doll, R.; et al. Dinaciclib (SCH 727965), a Novel and Potent Cyclin-Dependent Kinase Inhibitor. Mol. Cancer Ther. 2010, 9, 2344-2353. [CrossRef]

124. Paruch, K.; Dwyer, M.P.; Alvarez, C.; Brown, C.; Chan, T.-Y.; Doll, R.J.; Keertikar, K.; Knutson, C.; McKittrick, B.; Rivera, J.; et al. Discovery of Dinaciclib (SCH 727965): A Potent and Selective Inhibitor of Cyclin-Dependent Kinases. ACS Med. Chem. Lett. 2010, 1, 204-208. [CrossRef] [PubMed]

125. Barlaam, B.; Casella, R.; Cidado, J.; Cook, C.; De Savi, C.; Dishington, A.; Donald, C.S.; Drew, L.; Ferguson, A.D.; Ferguson, D.; et al. Discovery of AZD4573, a Potent and Selective Inhibitor of CDK9 That Enables Short Duration of Target Engagement for the Treatment of Hematological Malignancies. J. Med. Chem. 2020, 63, 15564-15590. [CrossRef] [PubMed]

126. Cidado, J.; Boiko, S.; Proia, T.; Ferguson, D.; Criscione, S.W.; Martin, M.S.; Pop-Damkov, P.; Su, N.; Franklin, V.N.R.; Chilamakuri, C.S.R.; et al. AZD4573 Is a Highly Selective CDK9 Inhibitor That Suppresses MCL-1 and Induces Apoptosis in Hematologic Cancer Cells. Clin. Cancer Res. 2019, 26, 922-934. [CrossRef]

127. Alcon, C.; Manzano-Muñoz, A.; Montero, J. A New CDK9 Inhibitor on the Block to Treat Hematologic Malignancies. Clin. Cancer Res. 2019, 26, 761-763. [CrossRef]

128. Rule, S.; Kater, A.P.; Brümmendorf, T.H.; Fegan, C.; Kaiser, M.; Radford, J.A.; Stilgenbauer, S.; Kayser, S.; Dyer, M.J.; Brossart, P.; et al. A phase 1, open-label, multicenter, non-randomized study to assess the safety, tolerability, pharmacokinetics, and preliminary antitumor activity of AZD4573, a potent and selective CDK9 inhibitor, in subjects with relapsed or refractory hematological malignancies. J. Clin. Oncol. 2018, 36, TPS7588. [CrossRef] 
129. Lücking, U.; Scholz, A.; Lienau, P.; Siemeister, G.; Kosemund, D.; Bohlmann, R.; Briem, H.; Terebesi, I.; Meyer, K.; Prelle, K.; et al. Identification of Atuveciclib (BAY 1143572), the First Highly Selective, Clinical PTEFb/CDK9 Inhibitor for the Treatment of Cancer. ChemMedChem 2017, 12, 1776-1793. [CrossRef]

130. NCT02345382 B. An open-label Phase I dose-escalation study to characterize the safety, tolerability, pharmacokinetics, and maximum tolerated dose of BAY 1143572 given in a once-daily or an intermittent dosing schedule in subjects with advanced acute leukemia. Available online: https://clinicaltrials.bayer.com/study/?id=16520\&Keyword=Atuveciclib\& gender $=\&$ ageRange $=\&$ Status $=\&$ Latitude $=\&$ Longitude $=\&$ MileRadius $=\&$ page $=0 \&$ SortField $=$ Location_Distance $\&$ SortOrder $=$ asc\&conditions $=\&$ phases $=\&$ healthy Vol=\&studyType=\&studyResult=\&locationCountryInternal=\&LocationName $=($ accessed on 14 May 2018).

131. NCT01938638 B. An open-label Phase I dose-escalation study to characterize the safety tolerability, pharmacokinetics, and maximum tolerated dose of BAY1143572 given in a once-daily or an intermittent dosing schedule in subjects with advanced malignancies. Available online: https://clinicaltrials.bayer.com/study/?id=16519\&Keyword=Atuveciclib\& gender $=\&$ ageRange $=\&$ Status $=\&$ Latitude $=\&$ Longitude $=\&$ MileRadius $=\&$ page $=0 \&$ SortField $=$ Location_Distance $\&$ SortOrder $=$ asc\&conditions $=\&$ phases $=\&$ healthy Vol=\&studyType $=\&$ studyResult=\&locationCountryInternal=\&LocationName $=$. (accessed on 12 February 2021).

132. Luecking, U.T.; Scholz, A.; Kosemund, D.; Bohlmann, R.; Briem, H.; Lienau, P.; Siemeister, G.; Terebesi, I.; Meyer, K.; Prelle, K.; et al. Abstract 984: Identification of potent and highly selective PTEFb inhibitor BAY 1251152 for the treatment of cancer: From p.o. to i.v. application via scaffold hops. Cancer Chem. 2017, 77, 984. [CrossRef]

133. Ferguson, F.M.; Gray, N.S. Kinase inhibitors: The road ahead. Nat. Rev. Drug Discov. 2018, 17, 353-377. [CrossRef] [PubMed]

134. Diamond, J.R.; Moreno, V.; Lim, E.A.; Cordoba, R.; Cai, C.; Ince, S.J.; Lettieri, J.T.; Merz, C.; Valencia, R.; Boni, V. Phase I dose escalation study of the first-in-class selective PTEFb inhibitor BAY 1251152 in patients with advanced cancer: Novel target validation and early evidence of clinical activity. J. Clin. Oncol. 2018, 36 (Suppl. 15), 2507. [CrossRef]

135. Byrne, M.; Frattini, M.G.; Ottmann, O.G.; Mantzaris, I.; Wermke, M.; Lee, D.J.; Morillo, D.; Scholz, A.; Ince, S.; Valencia, R.; et al. Phase I Study of the PTEFb Inhibitor BAY 1251152 in Patients with Acute Myelogenous Leukemia. Blood 2018, $132,4055$. [CrossRef]

136. Vincera Pharma. VIP152, a highly selective PTEFb /CDK9 inhibitor with encouraging Phase 1 monotherapy activity, including complete responses in DH-DLBCL. Available online: https://apnews.com/press-release/globe-newswire/virus-outbreaktechnology-business-licensing-agreements-corporate-news-bff559f275deea5fbedac769a500a11f (accessed on 8 February 2021).

137. Conroy, A.; Stockett, D.E.; Walker, D.; Arkin, M.R.; Hoch, U.; Fox, J.A.; Hawtin, R.E. SNS-032 is a potent and selective CDK 2 , 7 and 9 inhibitor that drives target modulation in patient samples. Cancer Chemother. Pharmacol. 2009, 64, 723-732. [CrossRef] [PubMed]

138. Albert, T.K.; Rigault, C.; Eickhoff, J.; Baumgart, K.; Antrecht, C.; Klebl, B.; Mittler, G.; Meisterernst, M. Characterization of molecular and cellular functions of the cyclin-dependent kinase CDK9 using a novel specific inhibitor. Br. J. Pharmacol. 2014, 171, 55-68. [CrossRef] [PubMed]

139. Heath, E.I.; Bible, K.; Martell, R.E.; Adelman, D.C.; Lorusso, P.M. A phase 1 study of SNS-032 (formerly BMS-387032), a potent inhibitor of cyclin-dependent kinases 2, 7 and 9 administered as a single oral dose and weekly infusion in patients with metastatic refractory solid tumors. Investig. New Drugs 2007, 26, 59-65. [CrossRef] [PubMed]

140. Tong, W.-G.; Chen, R.; Plunkett, W.; Siegel, D.; Sinha, R.; Harvey, R.D.; Badros, A.Z.; Popplewell, L.; Coutre, S.; Fox, J.A.; et al. Phase I and Pharmacologic Study of SNS-032, a Potent and Selective Cdk2, 7, and 9 Inhibitor, in Patients With Advanced Chronic Lymphocytic Leukemia and Multiple Myeloma. J. Clin. Oncol. 2010, 28, 3015-3022. [CrossRef] [PubMed]

141. Olson, C.M.; Jiang, B.; Erb, M.A.; Liang, Y.; Doctor, Z.M.; Zhang, Z.; Zhang, T.; Kwiatkowski, N.; Boukhali, M.; Green, J.L.; et al. Pharmacological perturbation of CDK9 using selective CDK9 inhibition or degradation. Nat. Chem. Biol. 2018, 14, 163-170. [CrossRef]

142. Wyatt, P.G.; Woodhead, A.J.; Berdini, V.; Boulstridge, J.A.; Carr, M.G.; Cross, D.M.; Davis, D.J.; Devine, L.A.; Early, T.R.; Feltell, R.E.; et al. Identification of N-(4-Piperidinyl)-4-(2,6-dichlorobenzoylamino)-1H-pyrazole-3-carboxamide (AT7519), a Novel Cyclin Dependent Kinase Inhibitor Using Fragment-Based X-Ray Crystallography and Structure Based Drug Design. J. Med. Chem. 2008, 51, 4986-4999. [CrossRef]

143. Squires, M.S.; Feltell, R.E.; Wallis, N.G.; Lewis, E.J.; Smith, D.-M.; Cross, D.M.; Lyons, J.F.; Thompson, N.T. Biological characterization of AT7519, a small-molecule inhibitor of cyclin-dependent kinases, in human tumor cell lines. Mol. Cancer Ther. 2009, 8 , 324-332. [CrossRef]

144. Squires, M.S.; Cooke, L.; Lock, V.; Qi, W.; Lewis, E.J.; Thompson, N.T.; Lyons, J.F.; Mahadevan, D. AT7519, a Cyclin-Dependent Kinase Inhibitor, Exerts Its Effects by Transcriptional Inhibition in Leukemia Cell Lines and Patient Samples. Mol. Cancer Ther. 2010, 9, 920-928. [CrossRef]

145. Mahadevan, D.; Plummer, R.; Squires, M.S.; Rensvold, D.; Dragovich, T.; Adams, J.; Lock, V.; Smith, D.; Von Hoff, D.D.; Calvert, H. A dose escalation, pharmacokinetic, and pharmacodynamic study of AT7519, a cyclin-dependent kinase inhibitor in patients with refractory solid tumors. J. Clin. Oncol. 2008, 26, 3533. [CrossRef]

146. Chen, E.X.; Hotte, S.; Hirte, H.; Siu, L.L.; Lyons, J.; Squires, M.; Lovell, S.; Turner, S.; McIntosh, L.; Seymour, L. A Phase I study of cyclin-dependent kinase inhibitor, AT7519, in patients with advanced cancer: NCIC Clinical Trials Group IND 177. Br. J. Cancer 2014, 111, 2262-2267. [CrossRef] [PubMed] 
147. Seftel, M.D.; Kuruvilla, J.; Kouroukis, T.; Banerji, V.; Fraser, G.; Crump, M.; Kumar, R.; Chalchal, H.I.; Salim, M.; Laister, R.C.; et al. The CDK inhibitor AT7519M in patients with relapsed or refractory chronic lymphocytic leukemia (CLL) and mantle cell lymphoma. A Phase II study of the Canadian Cancer Trials Group. Leuk. Lymphoma 2017, 58, 1358-1365. [CrossRef] [PubMed]

148. Do, K.T.; Chen, A.P.; Meehan, R.S.; Coyne, G.H.O.; Supko, J.G.; Trepel, J.B.; Clark, J.W.; Hays, J.L.; Lyons, J.F.; Keer, H.N.; et al. Phase 1 study of onalespib, HSP90 inhibitor, and AT7519M, CDK9 inhibitor, in patients with advanced solid tumors. J. Clin. Oncol. 2017, 35, TPS2617. [CrossRef]

149. Wang, B.; Wu, J.; Wu, Y.; Chen, C.; Zou, F.; Wang, A.; Wu, H.; Hu, Z.; Jiang, Z.; Liu, Q.; et al. Discovery of 4-(((4-(5-chloro-2-(((1s,4s)4-((2-methoxyethyl)amino)cyclohexyl)amino)pyridin-4-yl)thiazol-2-yl)amino)methyl)tetrahydro-2H-pyran-4-carbonitrile (JSH150) as a novel highly selective and potent CDK9 kinase inhibitor. Eur. J. Med. Chem. 2018, 158, 896-916. [CrossRef]

150. Yin, T.; Lallena, M.J.; Kreklau, E.L.; Fales, K.R.; Carballares, S.; Torrres, R.; Wishart, G.N.; Ajamie, R.T.; Cronier, D.M.; Iversen, P.W.; et al. A Novel CDK9 Inhibitor Shows Potent Antitumor Efficacy in Preclinical Hematologic Tumor Models. Mol. Cancer Ther. 2014, 13, 1442-1456. [CrossRef]

151. Fischer Peter, M.; Wang, S.; Zaytsev, A. Pyrimidines, triazines and their use as pharmaceutical agents. WO2009118567A2, 11 March 2010.

152. Walsby, E.; Pratt, G.; Shao, H.; Abbas, A.Y.; Fischer, P.M.; Bradshaw, T.D.; Brennan, P.; Fegan, C.; Wang, S.; Pepper, C. A novel Cdk9 inhibitor preferentially targets tumor cells and synergizes with fludarabine. Oncotarget 2013, 5, 375-385. [CrossRef] [PubMed]

153. Xie, S.; Jiang, H.; Zhai, X.-W.; Wei, F.; Wang, S.-D.; Ding, J.; Chen, Y. Antitumor action of CDK inhibitor LS-007 as a single agent and in combination with ABT-199 against human acute leukemia cells. Acta Pharmacol. Sin. 2016, 37, 1481-1489. [CrossRef] [PubMed]

154. Sorvina, A.; Shandala, T.; Wang, S.; Sharkey, D.J.; Parkinson-Lawrence, E.; Selemidis, S.; Brooks, D.A. CDKI-73 Is a Novel Pharmacological Inhibitor of Rab11 Cargo Delivery and Innate Immune Secretion. Cells 2020, 9, 372. [CrossRef]

155. Bettayeb, K.; Oumata, N.; Echalier, A.; Ferandin, Y.; A Endicott, J.; Galons, H.; Meijer, L. CR8, a potent and selective, roscovitinederived inhibitor of cyclin-dependent kinases. Oncogene 2008, 27, 5797-5807. [CrossRef]

156. Delehouze, C.; Godl, K.; Loaec, N.; Bruyere, C.; Desban, N.; Oumata, N.; Galons, H.; Roumeliotis, T.I.; Giannopoulou, E.G.; Grenet, J.; et al. CDK/CK1 inhibitors roscovitine and CR8 downregulate amplified MYCN in neuroblastoma cells. Oncogene 2013, 33, 5675-5687. [CrossRef] [PubMed]

157. De Falco, G.; Bellan, C.; D'Amuri, A.; Angeloni, G.; Leucci, E.; Giordano, A.; Leoncini, L. Cdk9 regulates neural differentiation and its expression correlates with the differentiation grade of neuroblastoma and PNET tumors. Cancer Biol. Ther. 2005, 4, $277-281$. [CrossRef]

158. Xu, J.; Xu, S.; Fang, Y.; Chen, T.; Xie, X.; Lu, W. Cyclin-dependent kinase 9 promotes cervical cancer development via AKT2/p53 pathway. IUBMB Life 2018, 71, 347-356. [CrossRef] [PubMed]

159. Gothert, J.R.; Imsak, R.; Mollmann, M.; Kesper, S.; Gobel, M.; Duhrsen, U.; Scholz, A.; Lucking, U.; Baumann, M.; Unger, A.; et al. Potent anti-leukemic activity of a specific cyclin-dependent kinase 9 inhibitor in mouse models of chronic lymphocytic leukemia. Oncotarget 2018, 9, 26353-26369. [CrossRef]

160. Juric, V.; Murphy, B. Cyclin-dependent kinase inhibitors in brain cancer: Current state and future directions. Cancer Drug Resist. 2020, 3, 48-62. [CrossRef]

161. Hellvard, A.; Zeitlmann, L.; Heiser, U.; Kehlen, A.; Niestroj, A.; DeMuth, H.-U.; Koziel, J.; Delaleu, N.; Potempa, J.; Mydel, P. Inhibition of CDK9 as a therapeutic strategy for inflammatory arthritis. Sci. Rep. 2016, 6, 31441. [CrossRef]

162. Matrone, G.; Wilson, K.S.; Maqsood, S.; Mullins, J.J.; Tucker, C.S.; Denvir, M.A. CDK9 and its repressor LARP7 modulate cardiomyocyte proliferation and response to injury in the zebrafish heart. J. Cell Sci. 2015, 128, 4560-4571. [CrossRef] [PubMed]

163. Chen, E.W.; Tay, N.Q.; Brzostek, J.; Gascoigne, N.R.J.; Rybakin, V. A Dual Inhibitor of Cdc7/Cdk9 Potently Suppresses T Cell Activation. Front. Immunol. 2019, 10. [CrossRef] [PubMed]

164. Zaborowska, J.; Isa, N.F.; Murphy, S. P-TEFb goes viral. Inside Cell 2016, 1, 106-116. [CrossRef] [PubMed]

165. Mandal, R.; Becker, S.; Strebhardt, K. Stamping out RAF and MEK1/2 to inhibit the ERK1/2 pathway: An emerging threat to anticancer therapy. Oncogene 2016, 35, 2547-2561. [CrossRef]

166. Mandal, R.; Raab, M.; Matthess, Y.; Becker, S.; Knecht, R.; Strebhardt, K. pERK $1 / 2$ inhibit Caspase-8 induced apoptosis in cancer cells by phosphorylating it in a cell cycle specific manner. Mol. Oncol. 2014, 8, 232-249. [CrossRef] [PubMed]

167. Duan, Y.-C.; Guan, Y.; Qin, W.; Zhai, X.; Yu, B.; Liu, H.-M. Targeting Brd4 for cancer therapy: Inhibitors and degraders. MedChemComm 2018, 9, 1779-1802. [CrossRef] [PubMed]

168. McCalmont, H.; Li, K.L.; Jones, L.; Toubia, J.; Bray, S.C.; Casolari, D.A.; Mayoh, C.; Samaraweera, S.E.; Lewis, I.D.; Prinjha, R.K.; et al. Efficacy of combined CDK9/BET inhibition in preclinical models of MLL-rearranged acute leukemia. Blood Adv. 2020, 4, 296-300. [CrossRef] [PubMed]

169. Gerlach, D.; Tontsch-Grunt, U.; Baum, A.; Popow, J.; Scharn, D.; Hofmann, M.H.; Engelhardt, H.; Kaya, O.; Beck, J.; Schweifer, N.; et al. The novel BET bromodomain inhibitor BI 894999 represses super-enhancer-associated transcription and synergizes with CDK9 inhibition in AML. Oncogene 2018, 37, 2687-2701. [CrossRef] [PubMed]

170. Moreno, N.; Holsten, T.; Mertins, J.; Zhogbi, A.; Johann, P.; Kool, M.; Meisterernst, M.; Kerl, K. Combined BRD4 and CDK9 inhibition as a new therapeutic approach in malignant rhabdoid tumors. Oncotarget 2017, 8, 84986-84995. [CrossRef] 
171. Piha-Paul, S.A.; Sachdev, J.C.; Barve, M.; Lorusso, P.; Szmulewitz, R.; Patel, S.P.; Lara, P.N., Jr.; Chen, X.; Hu, B.; Freise, K.J.; et al. First-in-Human Study of Mivebresib (ABBV-075), an Oral Pan-Inhibitor of Bromodomain and Extra Terminal Proteins, in Patients with Relapsed/Refractory Solid Tumors. Clin. Cancer Res. 2019, 25, 6309-6319. [CrossRef]

172. Patnaik, A.; Carvajal, R.D.; Komatsubara, K.M.; Britten, C.D.; Wesolowski, R.; Michelson, G.; Alcantar, O.; Zhang, C.; Powell, B.; Severson, P.; et al. Phase ib/2a study of PLX51107, a small molecule BET inhibitor, in subjects with advanced hematological malignancies and solid tumors. J. Clin. Oncol. 2018, 36, 2550. [CrossRef]

173. Mita, M.M.; Mita, A.C. Bromodomain inhibitors a decade later: A promise unfulfilled? Br. J. Cancer 2020, 123, 1713-1714. [CrossRef]

174. BRD4 inhibitors. Available online: https: / clinicaltrials.gov / ct2/results?recrs $=\&$ cond $=$ Cancer\&term $=B R D 4 \& c n t r y=\& s t a t e=$ $\&$ city $=\&$ dist $=$ (accessed on 12 February 2021).

175. Alfonso-Dunn, R.; Arbuckle, J.H.; Vogel, J.L.; Kristie, T.M. Inhibition of the Super Elongation Complex Suppresses Herpes Simplex Virus Immediate Early Gene Expression, Lytic Infection, and Reactivation from Latency. mBio 2020, 11. [CrossRef] [PubMed]

176. Liang, K.; Smith, E.R.; Aoi, Y.; Stoltz, K.L.; Katagi, H.; Woodfin, A.R.; Rendleman, E.J.; Marshall, S.A.; Murray, D.C.; Wang, L.; et al. Targeting Processive Transcription Elongation via SEC Disruption for MYC-Induced Cancer Therapy. Cell 2018, 175, 766-779.e17. [CrossRef]

177. HSP90 inhibitors. Available online: https://clinicaltrials.gov/ct2/results?recrs=\&cond=Cancer\&term=HSP90+inhibitors\&cntry= \&state $=\&$ city $=\&$ dist $=($ accessed on 12 February 2021).

178. Clinicaltrial. Available online: https: / clinicaltrials.gov / ct2 $/$ results?recrs $=\&$ cond=Cancer\&term $=M C L-1 \& c n t r y=\& s t a t e=\& c i t y=$ \&dist $=$ (accessed on 12 February 2021).

179. Bolomsky, A.; Vogler, M.; Köse, M.C.; Heckman, C.A.; Ehx, G.; Ludwig, H.; Caers, J. MCL-1 inhibitors, fast-lane development of a new class of anti-cancer agents. J. Hematol. Oncol. 2020, 13, 1-19. [CrossRef]

180. XIAP inhibitors. Available online: https://clinicaltrials.gov/ct2/results? recrs =\&cond=Cancer\&term $=$ XIAP+inhibitors\&cntry= \&state $=\&$ city $=\&$ dist $=($ accessed on 12 February 2021).

181. BCL-2 Inhibitors. Available online: https://clinicaltrials.gov/ct2/results?recrs=\&cond=Cancer\&term=BCL2+inhibitors\&cntry= \&state $=\&$ city $=\&$ dist $=($ accessed on 12 February 2021).

182. Lu, H.; Xue, Y.; Yu, G.K.; Arias, C.; Lin, J.; Fong, S.; Faure, M.; Weisburd, B.; Ji, X.; Mercier, A.; et al. Compensatory induction of MYC expression by sustained CDK9 inhibition via a BRD4-dependent mechanism. Elife 2015, 4, 06535.

183. Madden, S.K.; De Araujo, A.D.; Gerhardt, M.; Fairlie, D.P.; Mason, J.M. Taking the Myc out of cancer: Toward therapeutic strategies to directly inhibit c-Myc. Mol. Cancer 2021, 20, 1-18. [CrossRef] [PubMed]

184. Winters, A.C.; Bernt, K.M. MLL-Rearranged Leukemias-An Update on Science and Clinical Approaches. Front. Pediatr. 2017, 5, 4. [CrossRef]

185. Jovanović, K.K.; Roche-Lestienne, C.; Ghobrial, I.M.; Facon, T.; Quesnel, B.; Manier, S. Targeting MYC in multiple myeloma. Leukemia 2018, 32, 1295-1306. [CrossRef]

186. Ohanian, M.; Rozovski, U.; Kanagal-Shamanna, R.; Abruzzo, L.V.; Loghavi, S.; Kadia, T.; Futreal, A.; Bhalla, K.; Zuo, Z.; Huh, Y.O.; et al. MYC protein expression is an important prognostic factor in acute myeloid leukemia. Leuk. Lymphoma 2019, 60, 37-48. [CrossRef]

187. Polier, G.; Ding, J.; Konkimalla, B.; Eick, D.; Ribeiro, N.; Köhler, R.; Giaisi, M.; Efferth, T.; Desaubry, L.; Krammer, P.H.; et al. Wogonin and related natural flavones are inhibitors of CDK9 that induce apoptosis in cancer cells by transcriptional suppression of Mcl-1. Cell Death Dis. 2011, 2, e182. [CrossRef] [PubMed]

188. Polier, G.; Giaisi, M.; Köhler, R.; Müller, W.W.; Lutz, C.; Buss, E.C.; Krammer, P.H.; Li-Weber, M. Targeting CDK9 by wogonin and related natural flavones potentiates the anti-cancer efficacy of the Bcl-2 family inhibitor ABT-263. Int. J. Cancer 2014, 136, 688-698. [CrossRef] [PubMed] 